\title{
Simplifying Nature: Towards The Design of Broad Spectrum Kinetoplastid Inhibitors, Inspired by Acetogenins
}

Eoin R. Gould, Elizabeth F. B. King, Stefanie K. Menzies, Andrew L. Fraser, Lindsay B. Tulloch, Marija K. Zacharova, Terry K. Smith* and Gordon J. Florence*

EaStChem School of Chemistry,

Biomedical Science Research Complex,

University of St Andrews, North Haugh,

St Andrews, Fife,

KY16 9ST, UK

E-mail: gjf1@st-andrews.ac.uk; tks1@st-andrews.ac.uk

Keywords: neglected tropical diseases, acetogenins, tetrahydropyran, natural products

\begin{abstract}
The need for new treatments for the neglected tropical diseases African sleeping sickness, Chagas disease and Leishmaniasis remains urgent with the diseases widespread in tropical regions, affecting the world's very poorest. We have previously reported bis-tetrahydropyran 1,4-triazole analogues designed as mimics of the annonaceous acetogenin natural product chamuvarinin, which maintained trypanocidal activity. Building upon these studies, we here report related triazole compounds with pendant heterocycles, mimicking the original butenolide of the natural product. Analogues were active against $T$. brucei, with a nitrofuran compound displaying nanomolar trypanocidal activity. Several analogues also showed strong activity against T. cruzi and L. major. Importantly, select compounds gave excellent selectivity over mammalian cells with a furan-based analogue highly selective while remaining active against all three cell lines, thus representing a potential lead for a new broad spectrum kinetoplastid inhibitor.
\end{abstract}




\section{Introduction}

As defined by the World Health Organization, a neglected tropical disease (NTD) is a tropical infection that affects millions of people worldwide ${ }^{1}$ but has seen inadequate investigation into treatment. ${ }^{2,3}$ This $^{\text {is }}$ principally due to the limited financial incentive in treating such conditions, which is linked to their prevalence in developing countries where healthcare spending is low and health infrastructure is poor. Three such diseases are African sleeping sickness, ${ }^{4}$ Chagas disease ${ }^{5}$ and Leishmaniasis, ${ }^{6}$ spread by the related kinetoplastid parasitic causative agents Trypanosoma brucei, Trypanosoma cruzi and Leishmania $s p p$, respectively. These parasites are present in tropical regions across the world; T. brucei in subSaharan Africa, T. cruzi in South America and increasingly in North America ${ }^{7}$ and Leishmania throughout the tropics and sub-tropics. ${ }^{8}$ All three diseases share a genetic similarity and treatments developed for one specific disease have sometimes proved effective in treating another e.g. nifurtimox was originally developed for Chagas disease but has subsequently found application as a combination therapy for African sleeping sickness. ${ }^{9,10}$

The tropical plants of the Annonaceae species have long been known for their therapeutic properties, with the crude extracts of fruits, leaves, roots and bark used in traditional medicinal practices to treat a range of tropical diseases. ${ }^{11}$ Interest in this plant species as a source of potential new drugs intensified with the discovery of a family of fatty acid derived natural products, collectively termed the Annonaceous acetogenins, which now number in excess of $400 .^{12}$ Structurally, the acetogenins are C32/C34 fatty acids generally characterised by a central array of one to three tetrahydrofuran (THF) rings with flanking hydroxyl groups and appended with a terminal butenolide ring system as found in squamocin 1 and senegalene 2 (Figure 1). ${ }^{13}$ In contrast the tetrahydropyran (THP) ring system is less common and only seven acetogenins bear this motif including chamuvarinin $\mathbf{3}$. Members of this family 
of secondary metabolites are often highly cytotoxic displaying sub-nanomolar activity towards human cancer cell lines. $^{14}$

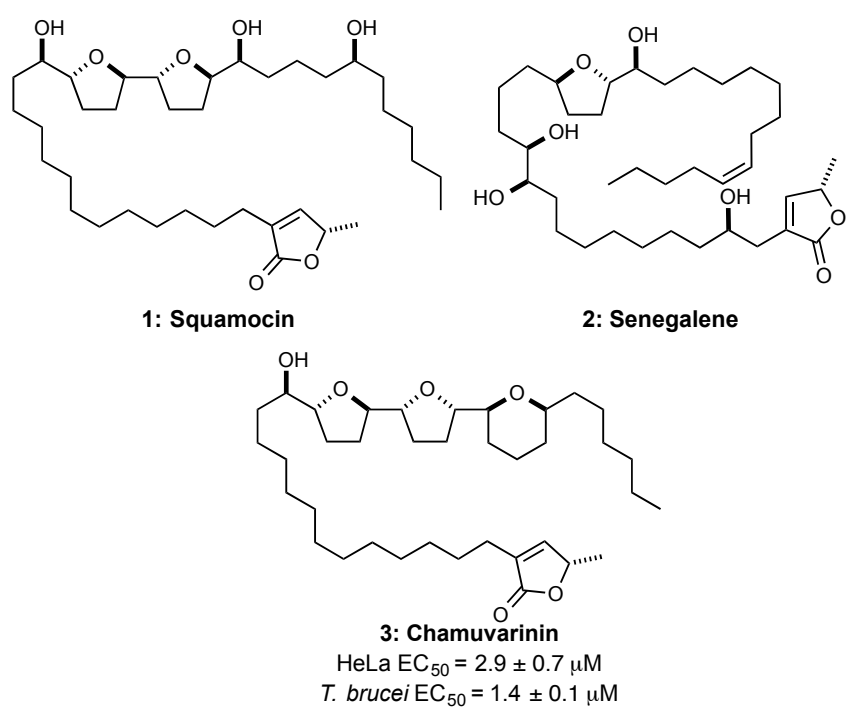

Figure 1 Annonaceous acetogenins with known anti-kinetoplastid activity

By contrast, the biological evaluation of acetogenins for the treatment of NTD has thus far been remarkably limited considering the wide scale use across sub-Saharan Africa of acetogenin-containing crude plant extracts to treat African sleeping sickness. ${ }^{15}$ Studies to date have primarily focussed on the phytochemical study of extracts from Annonaceae species for trypanocidal activity, with efforts focused on $T$. brucei, ${ }^{16}$ though select compounds such as squamocin $\mathbf{1}$ have shown encouraging preliminary activity against T. cruzi and Leishmania strains. ${ }^{17}$ In 2003 Laurens et al. reported that the root and bark extracts of Uvaria chamae are active towards T. brucei, which subsequently led to the isolation of chamuvarinin 3. ${ }^{18}$ Chamuvarinin is one of only seven acetogenins to contain a tetrahydropyran ring system and the only acetogenin to contain an all adjacently linked bis-THF-THP core ether ring system. In 2011, we reported the first total synthesis of chamuvarinin thereby establishing its absolute stereochemical structure. In addition our synthetic material displayed single figure micromolar activity towards the bloodstream form of T. brucei brucei, albeit with low selectivity over the HeLa human cell line. ${ }^{19}$ 
We built on these studies by designing a series of analogues inspired by chamuvarinin 3 that maintained T. brucei activity commensurate to that of the natural product (Figure 2 ) ${ }^{20}$ These analogues simplified the structure of chamuvarinin principally by replacing the central THF ring of the tricyclic core with a 1,4-triazole. This allowed rapid assembly of enantiomerically enriched THP building blocks via click chemistry, producing initial lead $\mathbf{4}$, which displayed low $(1.8 \mu \mathrm{M})$ trypanocidal activity against bloodstream form T. brucei. From this starting point, other features of the natural product were introduced, in particular the pendant butenolide, the orientation of which ('left- or right-hand side' as drawn) was critical to activity with $\mathbf{6}$ maintaining activity, while $\mathbf{5}$ was completely inactive. These results encouraged us to explore alternatives to the butenolide, principally on the azide, or 'left-hand side' of the molecule. Inspired by the work of Yamashita and co-workers, we have focused on simple aromatic heterocycles that were found to act as effective butenolide mimics. ${ }^{21}$ Our phenotypic screening program has now expanded to the other NTD parasite cell lines, T. cruzi and Leishmania major, so new potential inhibitors were evaluated against all three protozoa. ${ }^{22}$
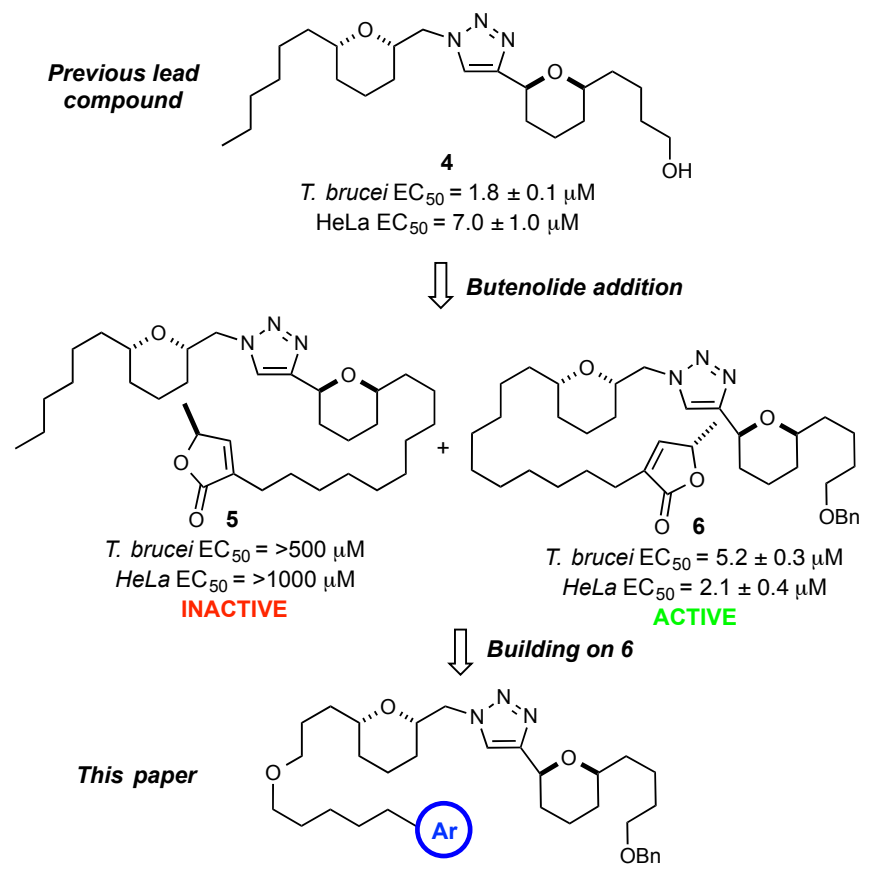

Figure 2 Directionality in our triazole based T. brucei inhibitors 


\section{Results and Discussion}

\subsection{Synthesis}

In order to rapidly access analogues with varying head groups, we targeted a THP precursor with an extended chain already present. Beginning from alcohol 7, mesylation followed by $\mathrm{S}_{\mathrm{N}} 2$ reaction with 6((triisopropylsilyl)oxy)hexan-1-ol generated alkene 8 (Scheme 1$){ }^{23}$ After racemic epoxidation, kinetic resolution with Jacobsen salen catalyst produced chiral epoxide 9 with $95 \%$ ee. ${ }^{24}$ Ring-opening with homoallyl magnesium bromide followed by epoxidation of the resulting double bond and in situ cyclisation generated THP alcohol $\mathbf{1 0}$ along with its diastereomeric pair (not shown) which were readily separated chromatographically. After conversion of the alcohol to azide 11 with DPPA, a "click" reaction with alkyne $\mathbf{1 2}$ generated the key THP-triazole-THP tricyclic core. Straightforward acidic deprotection then gave alcohol $\mathbf{1 3}$.

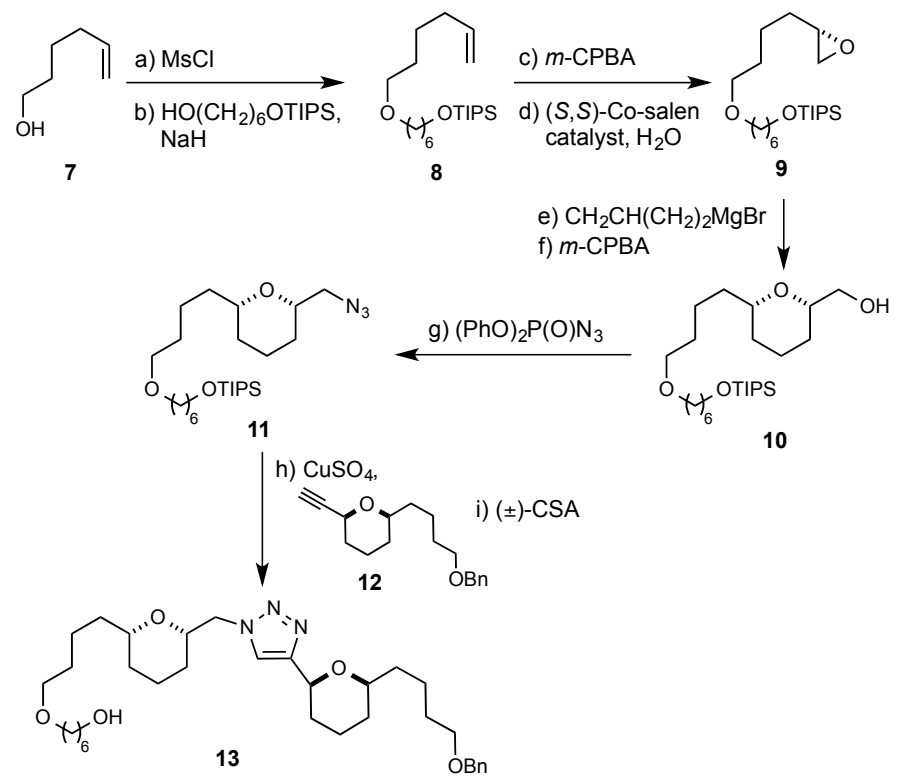

Scheme 1 Synthesis of starting material: a) $\mathrm{MsCl}, \mathrm{NEt}_{3}, \mathrm{CH}_{2} \mathrm{Cl}_{2}, 0{ }^{\circ} \mathrm{C} \rightarrow \mathrm{RT}$; b) $\mathrm{NaH}$, 6-((triisopropylsilyl)oxy)hexan-1-ol, THF, reflux, 91\% (2 steps); c) 3-chloroperbenzoic acid, $\mathrm{CH}_{2} \mathrm{Cl}_{2}, 0{ }^{\circ} \mathrm{C} \rightarrow \mathrm{RT}, 83 \%$; d) 0.6 mol\% $(S, S)$-Co-salen catalyst, 6 mol\% AcOH, $\mathrm{H}_{2} \mathrm{O}$, THF, 49\%; e) $\mathrm{CH}_{2} \mathrm{CHCH}_{2} \mathrm{CH}_{2} \mathrm{MgBr}$, CuI, THF, $-40{ }^{\circ} \mathrm{C} \rightarrow \mathrm{RT}, 84 \%$; f) 3-chloroperbenzoic acid, $\mathrm{CH}_{2} \mathrm{Cl}_{2}$, $0{ }^{\circ} \mathrm{C} \rightarrow \mathrm{RT}$; then $\left( \pm\right.$ )-camphorsulfonic acid (20 mol\%), RT, 43\% syn, 38\% anti; g) diphenylphosphoryl azide, $\mathrm{K}_{2} \mathrm{CO}_{3}, \mathrm{MeOH}$ $\mathrm{RT}, 83 \%$; h) $\mathrm{CuSO}_{4} .5 \mathrm{H}_{2} \mathrm{O}$, Na ascorbate, $\mathrm{H}_{2} \mathrm{O}, t$ - $\mathrm{BuOH}, \mathrm{RT}, 89 \%$; i) ( \pm )-camphorsulfonic acid $\left(20 \mathrm{~mol}^{2}\right), \mathrm{CH}_{2} \mathrm{Cl}_{2}: \mathrm{MeOH}_{\text {, }}$ RT, $88 \%$. 
Alcohol 13 served as a key point for derivatisation. Functional group interconversion of the alcohol via the azide provided amine $\mathbf{1 6}$ (Scheme 2). This then allowed the complete set of head group analogues 17-32 to be accessed via straightforward coupling with the appropriate acid in generally good yields. Targeted analogues focused on oxygen, nitrogen and sulfur containing five-membered aromatic heterocycles including furan, pyrrole and thiophene derivatives. ${ }^{21}$ For comparison with these compounds, benzylation of the free alcohol of $\mathbf{1 3}$ gave fully protected $\mathbf{1 4}$ while hydrogenation generated diol $\mathbf{1 5}$.
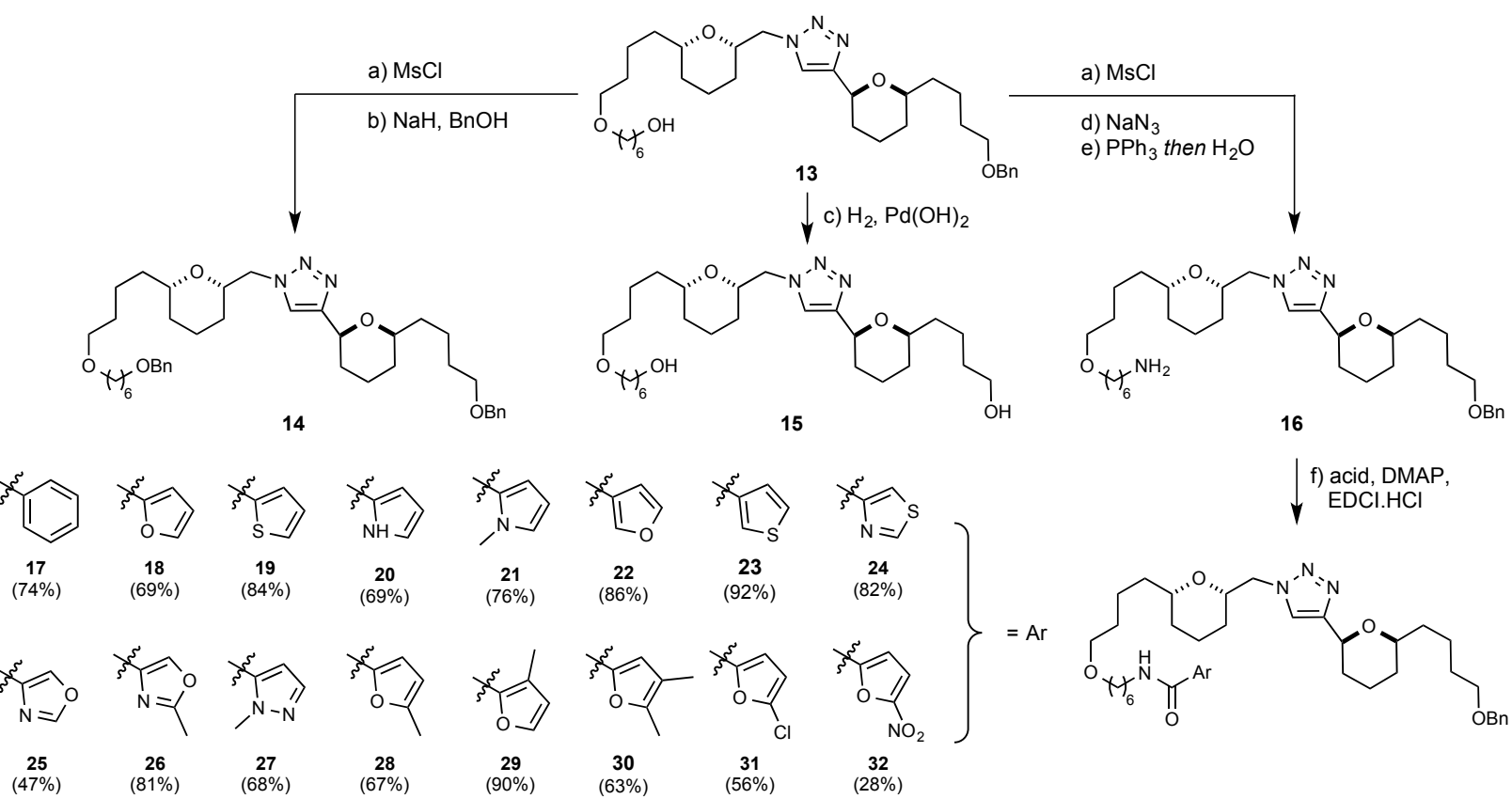

Scheme 2 Synthesis of analogues: a) $\mathrm{MsCl}, \mathrm{NEt}_{3}, \mathrm{CH}_{2} \mathrm{Cl}_{2}, 0{ }^{\circ} \mathrm{C} \rightarrow \mathrm{RT}, 87 \%$; b) $\mathrm{NaH}$, benzyl alcohol, THF, reflux, 33\%; c) $\mathrm{H}_{2}, \mathrm{Pd}(\mathrm{OH})_{2}$, EtOH, RT, 59\%; d) $\mathrm{NaN}_{3}$, DMF, $40{ }^{\circ} \mathrm{C}, 74 \%$; e) $\mathrm{PPh}_{3}$, THF, RT then $\mathrm{H}_{2} \mathrm{O}, 83 \%$; f) carboxylic acid, $N$-(3dimethylaminopropyl)- $N^{\prime}$-ethylcarbodiimide hydrochloride, $N$-dimethylaminopyridine, $\mathrm{CH}_{2} \mathrm{Cl}_{2}$, RT.

In an effort to separate the influence of the head group from that of the tricyclic core, a selection of heterocycles with simple alkyl chains were synthesised as controls (Scheme 3). Amide coupling of a pyrazole acid, furoic acid and 5-nitrofuroic acid with a simple amino alcohol gave the corresponding alcohols, which were then capped using trimethyloxonium tetrafluoroborate to give methylated analogues 33, 34 and 35 . 


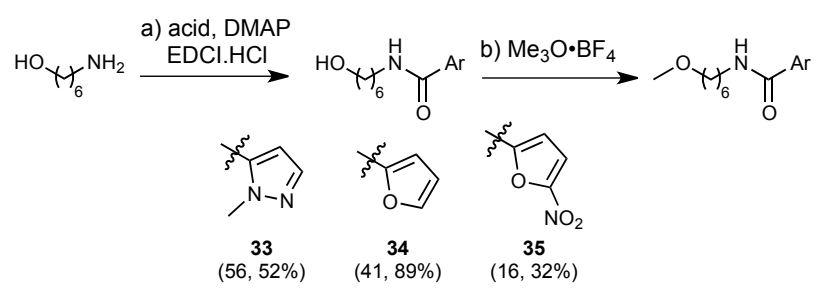

Scheme 3 Synthesis of control analogues: a) carboxylic acid, $N$-(3-dimethylaminopropyl)- $N$ '-ethylcarbodiimide hydrochloride, $\mathrm{N}$-dimethylaminopyridine, $\mathrm{CH}_{2} \mathrm{Cl}_{2}, \mathrm{RT}$; b) $\mathrm{Me}_{3} \mathrm{O} \cdot \mathrm{BF}_{4}, \mathrm{CH}_{2} \mathrm{Cl}_{2}, 0^{\circ} \mathrm{C} \rightarrow \mathrm{RT}$.

\subsection{Biological Testing}

We began our biological screening by testing relevant synthetic intermediates and compounds without head groups to give a baseline for activity (Table 1). All analogues were screened against our kinetoplastid cell lines: T. brucei, T. cruzi and L. major as well as the human HeLa cell line which we used to assess potential selectivity of our analogues over mammalian cells. ${ }^{25}$ All analogues were active at low micromolar concentrations in T. brucei, with the exception of diol $\mathbf{1 5},{ }^{26}$ consistent with the activity we have observed for the tricyclic core of our molecules (entry 3). In T. cruzi, $\mathbf{1 3}$ and $\mathbf{1 6}$ showed moderate activity, while di-benzyl $\mathbf{1 4}$ and diol $\mathbf{1 5}$ analogues were essentially inactive. In L. major, hydroxyl terminated $\mathbf{1 3}$ gave best inhibition at $12.4 \mu \mathrm{M}$ (entry 1) with all other analogues less active, though amine 16 had moderate $19.8 \mu \mathrm{M}$ activity (entry 4). Significantly, analogues showed HeLa inhibition comparable to the other lines tested indicating a general lack of selectivity for parasite cells over mammalian cells. 


\begin{tabular}{|c|c|c|c|c|c|}
\hline \multirow[b]{2}{*}{ Entry } & \multirow[b]{2}{*}{ Analogue } & \multirow[b]{2}{*}{$\begin{array}{c}\text { T. brucei } \\
\text { (BSF) EC } \text { ED }_{50} \\
(\mu \mathrm{M})\end{array}$} & $\mathrm{OR}^{2}$ & \multicolumn{2}{|c|}{$\begin{array}{l}13 \mathrm{R}^{1}=\mathrm{OH}, \mathrm{R}^{2}=\mathrm{Bn} \\
14 \mathrm{R}=\mathrm{OBn}, \mathrm{R}^{2}=\mathrm{Bn} \\
15 \mathrm{R}^{1}=\mathrm{OH}, \mathrm{R}^{2}=\mathrm{H} \\
16 \mathrm{R}=\mathrm{NH}_{2}, \mathrm{R}^{2}=\mathrm{Bn}\end{array}$} \\
\hline & & & $\begin{array}{l}\text { T. cruzi } \\
\mathrm{EC}_{50} \\
(\mu \mathrm{M})\end{array}$ & $\begin{array}{l}\text { L. major } \\
\mathrm{EC}_{50} \\
(\mu \mathrm{M})\end{array}$ & $\begin{array}{l}\text { HeLa } \\
\mathrm{EC}_{50} \\
(\mu \mathrm{M})\end{array}$ \\
\hline 1 & 13 & $3.5 \pm 0.3$ & $27.3 \pm 1.0$ & $12.4 \pm 0.9$ & $21.6 \pm 1.3$ \\
\hline 2 & 14 & $4.3 \pm 0.3$ & $>500$ & $411 \pm 25$ & $>20^{*}$ \\
\hline 3 & 15 & $37.7 \pm 3.1$ & $230 \pm 19$ & $123 \pm 3$ & $69.3 \pm 5.6$ \\
\hline 4 & 16 & $5.8 \pm 0.5$ & $16.7 \pm 0.7$ & $19.2 \pm 0.6$ & $8.1 \pm 0.6$ \\
\hline
\end{tabular}

Table 1 Synthetic intermediates and non-head group analogues (*Toxicity likely due to biophysical effect, rather than ontarget interaction)

With selectivity a primary concern, an initial set of our amide analogues was screened against the same cell lines (Table 2). Select compounds were also screened against the Vero cell line as a secondary, noncancerous mammalian cell line to further assess selectivity over mammalian cells. For T. brucei, heterocycle incorporation was well tolerated with all analogues tested falling within a narrow range of 3.8 to $8.4 \mu \mathrm{M}$, the best of these being 2-furan $\mathbf{1 8}$ (entry 2). The results in $T$. cruzi displayed significantly more variation with furan 18 the most active compound at $8.0 \mu \mathrm{M}$ inhibition (entry 2). Interestingly, any change of the heteroatom in the simple heterocycles away from oxygen removed activity, as did a change to 3-hetero substitution (entries 3-7). By contrast, 1,3-azoles displayed modest activity, the best being thiazole 24 (entry 8 ) and methyl oxazole 26 (entry 10). 3-Hetero substitution was tolerated in $L$. major (entries 6 and 7), as were 1,3-azoles (entries 8-10) but again the best compound was furan $\mathbf{1 8}$ at $7.8 \mu \mathrm{M}$ (entry 2$)$.

Most pleasingly, the majority of analogues were essentially inactive against the HeLa cell line, with the exception of oxazoles $\mathbf{2 5}$ and $\mathbf{2 6}$ (entries 9 and 10). This implies potential added selectivity for parasite over mammalian cells, an essential criterion for any new therapeutic treatment. Furthermore, almost identical results to HeLa were obtained with selected analogues against Vero cells, with lead compound 
18 showing no activity against both of these mammalian cell lines. The broad-spectrum anti-parasitic activity and selectivity of $\mathbf{1 8}$ was highly encouraging and led us to explore additional furan head groups below. $^{27}$

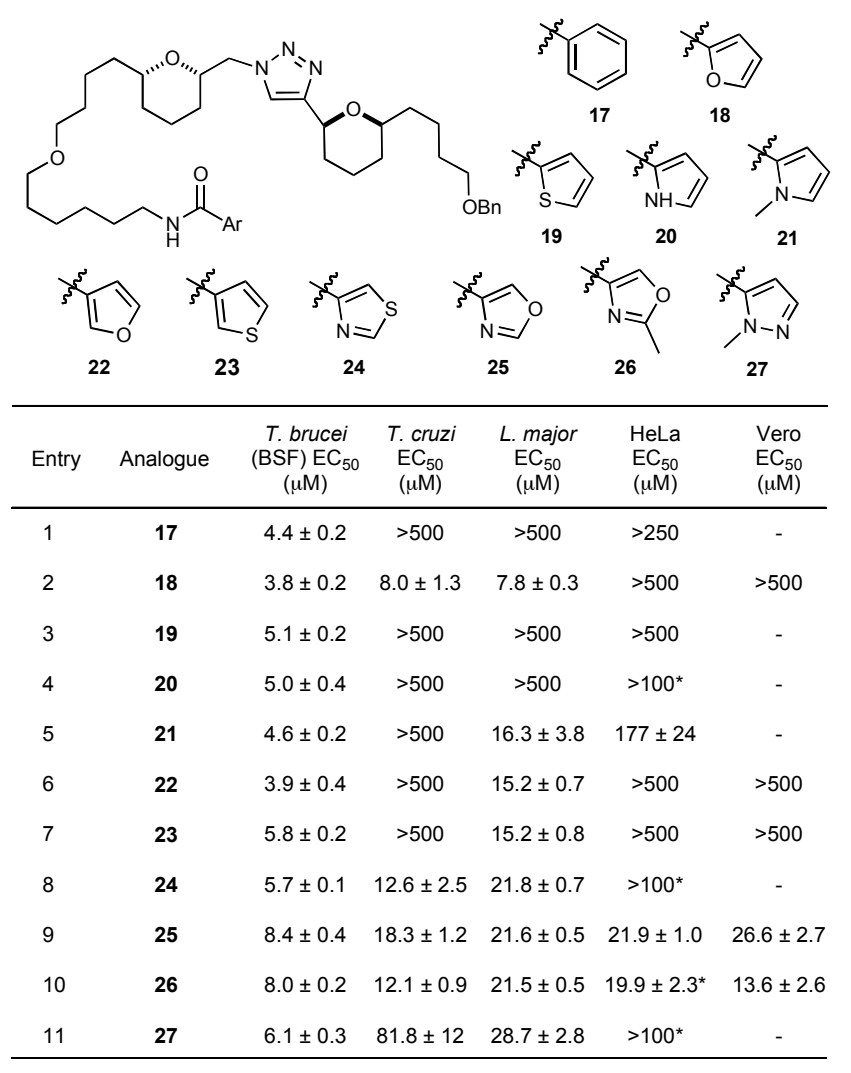

Table 2 Initial set of inhibitors 17-27 (*Toxicity likely due to biophysical effect, rather than on-target interaction)

We next curated a series of analogues in order to probe both steric and electronic variation of the pendant furan (Table 3). In T. brucei, methyl substitution (entries 2-4) was tolerated across the furan ring without loss of activity, as was a moderately electron withdrawing chloride group (entry 5). Introduction of a nitro group in $\mathbf{3 2}$ led to a step-change improvement in activity, down to $37.3 \mathrm{nM}$ (entry 6). By contrast, in T. cruzi any perturbation of the furan was detrimental to activity with all analogues greater than $100 \mu \mathrm{M}$, the only exception being nitro compound $\mathbf{3 2}$ with slightly improved activity (entry 6). For L. major, 5-methyl and 5-nitro substitution was tolerated (entries 2 and 6) but changing the substitution position or adding electron-withdrawing groups gave reduced activity (entries 3-5). The 
compounds showed generally moderate to no activity against HeLa with nitro compound $\mathbf{3 2}$ once again the exception at $0.38 \mu \mathrm{M} .32$ was also examined in Vero with an $\mathrm{EC}_{50}$ of $4.5 \mu \mathrm{M}$.

Although the results for $\mathbf{3 2}$ are encouraging, particularly the excellent activity in T. brucei, it should be noted that 5-nitroheterocycles are well known to have activity against T. brucei and T. cruzi and thus we were conscious the increased activity of $\mathbf{3 2}$ may result from the nitrofuran head group, with the tricyclic core possibly only helping in cellular localisation. ${ }^{3,28}$ We thus accessed pyrazole $\mathbf{3 3}$, furan $\mathbf{3 4}$ and nitrofuran 35 that contain a head group and a simple alkyl chain only to aid solubility. We were pleased to see that $\mathbf{3 3}$ and $\mathbf{3 4}$ were essentially inactive in all lines tested- indicating the primacy of the tricyclic core in these analogues (entries 7 and 8). As expected, nitrofuran 35 showed activity in all cell lines, with the results in T. cruzi, L. major and HeLa broadly in line with those of $\mathbf{3 2}$ (compare entries 6 and 8 ). However, although activity was sub-micromolar in T. brucei, this nonetheless represents an almost a 20fold reduction in activity from $\mathbf{3 2}$ to $\mathbf{3 5}$, suggesting a synergistic effect between the tricyclic core of $\mathbf{3 2}$ and the nitrofuran head group. The exact nature of this effect remains under investigation. 


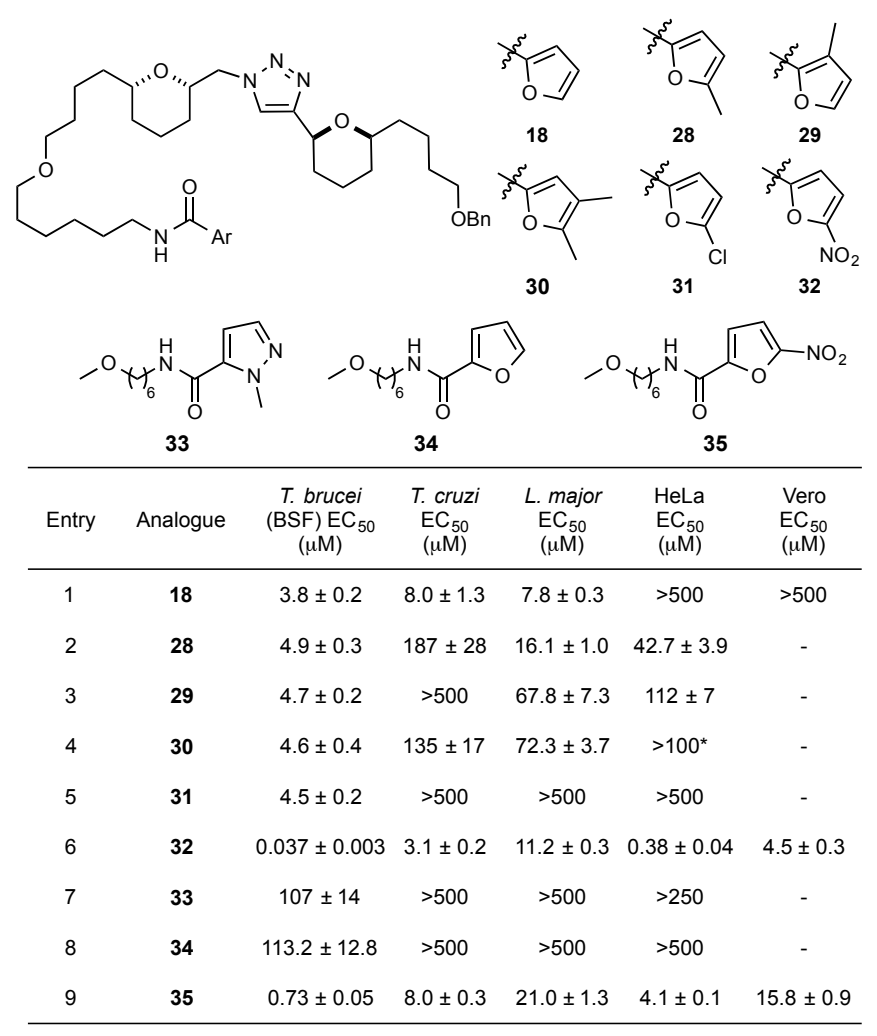

Table 3 Furan based inhibitors 18, 28-35 (*Toxicity likely due to biophysical effect, rather than on-target interaction)

\section{Conclusion}

In summary, we have accessed a new series based upon the previously established THP-triazole-THP motif incorporating a series of heterocycles in a position to mimic the butenolide core of our original natural product inspiration, chamuvarinin. These analogues displayed significant activity in a range of kinetoplastid parasite cell lines; T. brucei, T. cruzi and L. major, with some analogues also showing selectivity over mammalian cell lines Vero and HeLa. Two compounds stand out from the screen: the furan 18 displayed low micromolar activity in all parasite cell lines with excellent selectivity and thus represents a starting point for a potential broad spectrum kinetoplastid inhibitor. Nitrofuran $\mathbf{3 2}$ displayed nanomolar T. brucei inhibition, with promising selectivity over human cell lines. Our current efforts are 
focused on further SAR studies of these key compounds, including expansion into the other heterocyclic linker series currently under investigation within our team.

\section{Experimental}

\subsection{Chemistry}

Synthetic details for tested compounds are described below. For details of the synthesis of intermediates, see Supporting Information.

\subsubsection{General procedure for amide coupling}

The appropriate carboxylic acid (34.2 $\mu \mathrm{mol}, 2 \mathrm{eq})$, EDCI.HCl $(5.30 \mathrm{mg}, 34.2 \mu \mathrm{mol}, 2 \mathrm{eq})$ and DMAP $(17.1 \mu \mathrm{mol}, 1 \mathrm{eq})$ were combined in $\mathrm{CH}_{2} \mathrm{Cl}_{2}(2 \mathrm{~mL})$ and stirred at $\mathrm{RT}$ for $10 \mathrm{~min}$. Amine 15 (10.0 $\mathrm{mg}$, $17.1 \mu \mathrm{mol}, 1 \mathrm{eq})$ was added and the resulting mixture stirred at RT overnight. Reaction was, quenched by the addition of saturated aqueous $\mathrm{NH}_{4} \mathrm{Cl}$ solution $(5 \mathrm{~mL})$, extracted with EtOAc $(3 \times 5 \mathrm{~mL})$ and the combined organic layers washed with $0.1 \mathrm{M}$ aqueous $\mathrm{KOH}$ solution, brine, dried $\left(\mathrm{MgSO}_{4}\right)$, filtered and concentrated in vacuo.

\subsection{Compounds}

\subsubsection{6-(4-((2S,6S)-6-((4-((2S,6S)-6-(4-(benzyloxy)butyl)tetrahydro-2H-pyran-2-yl)-1H-1,2,3-} triazol-1-yl)methyl)tetrahydro-2H-pyran-2-yl)butoxy)hexan-1-ol 13

To a solution of 4-((2S,6S)-6-(4-(benzyloxy)butyl)tetrahydro-2H-pyran-2-yl)-1-(((2S,6S)-6-(4-((6((triisopropylsilyl)oxy)hexyl)oxy)butyl)tetrahydro-2H-pyran-2-yl)methyl)-1H-1,2,3-triazole S6 (1.62 g, $2.18 \mathrm{mmol})$ in methanol $(15 \mathrm{~mL})$ and $\mathrm{CH}_{2} \mathrm{Cl}_{2}(15 \mathrm{~mL})$ was added a solution of $( \pm)$-CSA $(101 \mathrm{mg}, 0.440$ mmol) in methanol $(5 \mathrm{~mL})$ and the mixture stirred at RT for $48 \mathrm{~h}$. Reaction was quenched by the addition of saturated aqueous $\mathrm{NaHCO}_{3}(30 \mathrm{~mL})$. The mixture was extracted with $\mathrm{CH}_{2} \mathrm{Cl}_{2}(3 \times 30 \mathrm{~mL})$ and the combined organic extracts washed with brine, dried $\left(\mathrm{MgSO}_{4}\right)$, filtered and concentrated in vacuo. Purification by flash column chromatography (60\% EtOAc/Hexane) provided alcohol 13 (1.12 g, 88\%), as a colourless oil. 
$\mathbf{R}_{\mathbf{f}} 0.17\left(50 \%\right.$ EtOAc/Hexane); $[\alpha]_{\mathrm{D}}^{20}-19\left(c\right.$ 0.40, $\left.\mathrm{CHCl}_{3}\right)$; IR (ATR) 3406, 2932, 2855, $1734 \mathrm{~cm}^{-1} ;{ }^{1} \mathbf{H}$ NMR $\left(400 \mathrm{MHz}, \mathrm{CDCl}_{3}\right) \delta 7.60\left(1 \mathrm{H}, \mathrm{s}, \underline{\mathrm{H}}_{\mathrm{Ar}}\right), 7.35-7.24(5 \mathrm{H}, \mathrm{m}, \operatorname{Ar} \underline{\mathrm{H}}), 4.59(1 \mathrm{H}, \mathrm{dd}, J=10.9,1.8 \mathrm{~Hz}$, $\left.\underline{\mathrm{H}}_{1}\right), 4.48\left(2 \mathrm{H}, \mathrm{s}, \mathrm{OC} \underline{H}_{2} \mathrm{Ar}\right), 4.42\left(1 \mathrm{H}, \mathrm{dd}, J=14.0,3.3 \mathrm{~Hz}, \underline{\mathrm{H}}_{1 \mathrm{a}}\right), 4.19\left(1 \mathrm{H}, \mathrm{dd}, J=14.0,8.0 \mathrm{~Hz}, \underline{\mathrm{H}}_{1 \mathrm{~b}}\right)$, 3.67-3.60 (1H, m, $\left.\underline{\mathrm{H}}_{2}\right), 3.61\left(2 \mathrm{H}, \mathrm{t}, J=6.6 \mathrm{~Hz}, \underline{\mathrm{H}}_{16}\right), 3.49-3.44\left(1 \mathrm{H}, \mathrm{m}, \underline{\mathrm{H}}_{5}\right), 3.46\left(2 \mathrm{H}, \mathrm{t}, J=6.6 \mathrm{~Hz}, \underline{\mathrm{H}}_{9}\right)$ ), $3.37\left(2 \mathrm{H}, \mathrm{t}, J=6.7 \mathrm{~Hz}, \underline{\mathrm{H}}_{10}\right), 3.36\left(2 \mathrm{H}, \mathrm{t}, J=6.8 \mathrm{~Hz}, \underline{\mathrm{H}}_{11}\right), 3.24-3.19\left(1 \mathrm{H}, \mathrm{m}, \underline{\mathrm{H}}_{6}\right), 2.02-1.83\left(3 \mathrm{H}, \mathrm{m}, \underline{\mathrm{H}}_{3 \mathrm{a}}\right.$ ' $\left.+\underline{\mathrm{H}}_{4}\right), 1.66-1.14\left(29 \mathrm{H}, \mathrm{m}, \underline{\mathrm{H}}_{2}{ }^{\prime}-4,+\underline{\mathrm{H}}_{3 \mathrm{~b}}+\underline{\mathrm{H}}_{5}+\underline{\mathrm{H}}_{6^{\prime}-8},+\underline{\mathrm{H}}_{7-9}+\underline{\mathrm{H}}_{12-15}\right) ;{ }^{13} \mathbf{C} \mathbf{N M R}\left(100 \mathrm{MHz}, \mathrm{CDCl}_{3}\right) \delta$ 150.0, 138.8, 128.5, 127.7, 127.6, 122.4, 78.4, 77.8, 76.2, 73.3, 73.0, 71.0, 70.9, 70.5, 62.9, 55.1, 36.4, 36.2, 32.8, 31.9, 31.3 31.2, 29.9, 29.8, 29.7, 28.7, 26.1, 25.7, 23.7, 23.1, 22.4, 22.3; HRMS (ESI ${ }^{+}$) Calc. for $\mathrm{C}_{34} \mathrm{H}_{56} \mathrm{O}_{5} \mathrm{~N}_{3}[\mathrm{M}+\mathrm{H}]^{+}$586.4214, found 586.4207.

\subsubsection{4-((2S,6S)-6-(4-(benzyloxy)butyl)tetrahydro-2H-pyran-2-yl)-1-(((2S,6S)-6-(4-((6- (benzyloxy)hexyl)oxy)butyl)tetrahydro-2H-pyran-2-yl)methyl)-1H-1,2,3-triazole 14}

To a solution of sodium hydride $(6.00 \mathrm{mg}$ of $60 \%$ dispersion in mineral oil, $151 \mu \mathrm{mol})$ in dry THF $(2 \mathrm{ml})$ at RT was added benzyl alcohol $(15.6 \mu \mathrm{L}, 151 \mu \mathrm{mol})$. After $15 \mathrm{~min}$, a solution of 6-(4-((2S,6S)-6-((4((2S,6S)-6-(4-(benzyloxy)butyl)tetrahydro-2H-pyran-2-yl)-1H-1,2,3-triazol-1-yl)methyl)tetrahydro- $2 H$ pyran-2-yl)butoxy)hexyl methanesulfonate $\mathbf{S} 7(20.0 \mathrm{mg}, 30.1 \mu \mathrm{mol})$ in dry THF $(2 \mathrm{~mL})$ was added and the mixture heated at reflux overnight. The mixture was diluted with water $(10 \mathrm{~mL})$ and extracted with $\mathrm{Et}_{2} \mathrm{O}(3 \times 10 \mathrm{~mL})$. The combined organic extracts were washed with brine, dried $\left(\mathrm{MgSO}_{4}\right)$ and concentrated in vacuo. Purification by flash column chromatography (10\% Acetone/Hexane) afforded ether $14(6.7 \mathrm{mg}, 33 \%)$, as a colourless oil.

$\mathbf{R}_{\mathbf{f}} 0.41$ (20\% Acetone/Hexane); $[\alpha]_{\mathrm{D}}^{20}-16\left(c\right.$ 0.64, $\left.\mathrm{CHCl}_{3}\right)$; IR (ATR) 2932, 2855, $1724 \mathrm{~cm}^{-1} ;{ }^{1} \mathbf{H}$ NMR $\left(400 \mathrm{MHz} \mathrm{CDCl}_{3}\right) \delta 7.60\left(1 \mathrm{H}, \mathrm{s}, \underline{\mathrm{H}}_{\mathrm{Ar}}\right), 7.38-7.24(10 \mathrm{H}, \mathrm{m}, \mathrm{Ar} \underline{\mathrm{H}}), 4.59\left(1 \mathrm{H}, \mathrm{dd}, J=10.9,1.8 \mathrm{~Hz}, \underline{\mathrm{H}}_{1}\right)$ ), $4.49\left(2 \mathrm{H}, \mathrm{s}, \mathrm{OCH}_{2} \mathrm{Ar}\right), 4.48\left(2 \mathrm{H}, \mathrm{s}, \mathrm{OCH}_{2} \mathrm{Ar}\right), 4.43\left(1 \mathrm{H}, \mathrm{dd}, J=14.0,3.4 \mathrm{~Hz}, \underline{\mathrm{H}}_{1 \mathrm{a}}\right), 4.19(1 \mathrm{H}, \mathrm{dd}, J=$ 14.0, 8.0 Hz, $\left.\underline{\mathrm{H}}_{1 \mathrm{~b}}\right), 3.67-3.61\left(1 \mathrm{H}, \mathrm{m}, \underline{\mathrm{H}}_{2}\right), 3.50-3.44\left(1 \mathrm{H}, \mathrm{m}, \underline{\mathrm{H}}_{5}\right), 3.46\left(2 \mathrm{H}, \mathrm{t}, J=6.6 \mathrm{~Hz}, \underline{\mathrm{H}}_{16}\right), 3.46(2 \mathrm{H}$, t, $\left.J=6.6 \mathrm{~Hz}, \underline{\mathrm{H}}_{9}\right), 3.37\left(2 \mathrm{H}, \mathrm{t}, J=6.4 \mathrm{~Hz}, \underline{\mathrm{H}}_{10}\right), 3.36\left(2 \mathrm{H}, \mathrm{t}, J=6.9 \mathrm{~Hz}, \underline{\mathrm{H}}_{11}\right), 3.24-3.19\left(1 \mathrm{H}, \mathrm{m}, \underline{\mathrm{H}}_{6}\right)$, 2.03-1.83 (3H, m, $\left.\underline{\mathrm{H}}_{3 \mathrm{a}}{ }^{\prime}+\underline{\mathrm{H}}_{4}\right)$, 1.66-1.14 (29H, m, $\left.\underline{\mathrm{H}}_{2}{ }^{\prime}-4, \underline{\mathrm{H}}_{3 \mathrm{~b}}+\underline{\mathrm{H}}_{5}+\underline{\mathrm{H}}_{6}{ }^{\prime}-8{ }^{\prime}+\underline{\mathrm{H}}_{7-9}+\underline{\mathrm{H}}_{12-15}\right) ;{ }^{13} \mathbf{C} \mathbf{N M R}$ $\left(100 \mathrm{MHz}, \mathrm{CDCl}_{3}\right) \delta 150.0,138.8(2 \mathrm{C}), 128.5$ (2C), 127.7 (2C), 127.6 (2C), 122.4, 78.4, 77.9, 76.3, 73.3, 73.0 (2C), 71.1, 70.9, 70.6, 70.5, 55.1, 36.4, 36.2, 31.9, 31.4, 31.3, 30.0, 29.9 (2C), 29.8, 28.7, 26.2 (2C), 23.8, 23.1, 22.3, 22.2; HRMS (ESI ${ }^{+}$) Calc. for $\mathrm{C}_{41} \mathrm{H}_{61} \mathrm{O}_{5} \mathrm{~N}_{3} \mathrm{Na}[\mathrm{M}+\mathrm{Na}]^{+}$698.4503, found 698.4481. 


\subsubsection{6-(4-((2S,6S)-6-((4-((2S,6S)-6-(4-hydroxybutyl)tetrahydro-2H-pyran-2-yl)-1H-1,2,3-triazol-1- yl)methyl)tetrahydro-2H-pyran-2-yl)butoxy)hexan-1-ol 15}

To a solution of alcohol $13(20.0 \mathrm{mg}, 34.1 \mu \mathrm{mol})$ in EtOH $(2 \mathrm{~mL})$ at RT was added $\mathrm{Pd}(\mathrm{OH})_{2}$ on carbon (6.50 $\mathrm{mg}$ of $20 \% \mathrm{wt}$ on carbon, $6.82 \mu \mathrm{mol})$. The reaction system was purged with $\mathrm{H}_{2}$ and left under a positive pressure of $\mathrm{H}_{2}$ overnight. The reaction mixture was filtered through Celite and washed with EtOH. The filtrate was concentrated in vacuo and purification by flash column chromatography (EtOAc then 3\% MeOH/EtOAc) provided diol 15 (10.0 mg, 59\%), as a colourless oil.

$\mathbf{R}_{\mathbf{f}} 0.24$ (EtOAc); $[\alpha]_{\mathrm{D}}^{20}-22$ (c 1.0, $\mathrm{CHCl}_{3}$ ); IR (ATR) 3360, 2932, $2857 \mathrm{~cm}^{-1} ;{ }^{1} \mathbf{H}$ NMR $(300 \mathrm{MHz}$, $\left.\mathrm{CDCl}_{3}\right) \delta 7.62\left(1 \mathrm{H}, \mathrm{s}, \underline{\mathrm{H}}_{\mathrm{Ar}}\right), 4.59\left(1 \mathrm{H}, \mathrm{dd}, J=10.9,1.8 \mathrm{~Hz}, \underline{\mathrm{H}}_{1}\right), 4.44\left(1 \mathrm{H}, \mathrm{dd}, J=14.0,3.2 \mathrm{~Hz}, \underline{\mathrm{H}}_{1 \mathrm{a}}\right)$, $4.20\left(1 \mathrm{H}, \mathrm{dd}, J=14.0,8.0 \mathrm{~Hz}, \underline{\mathrm{H}}_{1 \mathrm{~b}}\right), 3.68-3.60\left(1 \mathrm{H}, \mathrm{m}, \underline{\mathrm{H}}_{2}\right), 3.62\left(2 \mathrm{H}, \mathrm{t}, J=6.3 \mathrm{~Hz}, \underline{\mathrm{H}}_{16}\right), 3.61(2 \mathrm{H}, \mathrm{t}, J=$ $\left.6.6 \mathrm{~Hz}, \underline{\mathrm{H}}_{9}\right), 3.53-3.45\left(1 \mathrm{H}, \mathrm{m}, \underline{\mathrm{H}}_{5}\right), 3.33\left(2 \mathrm{H}, \mathrm{t}, J=6.6 \mathrm{~Hz}, \underline{\mathrm{H}}_{10}\right), 3.36\left(2 \mathrm{H}, \mathrm{t}, J=6.5 \mathrm{~Hz}, \underline{\mathrm{H}}_{11}\right), 3.24-$ $3.18\left(1 \mathrm{H}, \mathrm{m}, \underline{\mathrm{H}}_{6}\right), 2.05-1.86\left(3 \mathrm{H}, \mathrm{m}, \underline{\mathrm{H}}_{3 \mathrm{a}^{\prime}}+\underline{\mathrm{H}}_{4}\right), 1.70-1.13\left(29 \mathrm{H}, \mathrm{m}, \underline{\mathrm{H}}_{2}{ }^{\prime}-4,+\underline{\mathrm{H}}_{3 \mathrm{~b}}+\underline{\mathrm{H}}_{5}+\underline{\mathrm{H}}_{6^{\prime}-8^{\prime}}+\underline{\mathrm{H}}_{7-9}+\underline{\mathrm{H}}_{12-}\right.$ 15); ${ }^{13}$ C NMR (75 MHz, $\left.\mathrm{CDCl}_{3}\right) \delta 149.9,122.4,78.4,77.8,76.2,73.3,71.0,70.9,62.9,62.8,55.1,36.2$ (2C), 32.8, 32.8, 31.7, 31.4, 31.3, 29.8 (2C), 28.7, 26.1, 25.7, 23.7, 23.1, 22.2, 21.9; HRMS (ESI ${ }^{+}$) Calc. for $\mathrm{C}_{27} \mathrm{H}_{49} \mathrm{O}_{5} \mathrm{~N}_{3} \mathrm{Na}[\mathrm{M}+\mathrm{Na}]^{+}$518.3564, found 518.3549.

\subsubsection{4-[(2S',6S')-6'-(4-((6-aminohexyl)oxy)butyl)tetrahydropyran-2-yl]-1-[(2S', 6S'')-6'-(4-} hydroxybutyltetrahydropyran-2-yl)methyl]-1H-1,2,3-triazole 16

To a solution of 4-[(2S',6S')-6'-(4-((6-azidohexyl)oxy)butyl)tetrahydropyran-2-yl]-1-[(2S',6S' ')-6"'-(4hydroxybutyltetrahydropyran-2-yl)methyl]-1H-1,2,3-triazole (251 mg, $0.411 \mathrm{mmol})$ S7 in THF (4 mL) at $0{ }^{\circ} \mathrm{C}$ was added $\mathrm{PPh}_{3}(162 \mathrm{mg}, 0.617 \mathrm{mmol})$. The reaction mixture was stirred at $\mathrm{RT}$ overnight, then quenched with water (12 drops) and concentrated in vacuo. Purification by flash column chromatography ( $5 \% \mathrm{MeOH} / 1 \% \mathrm{NEt}_{3} / \mathrm{CH}_{2} \mathrm{Cl}_{2}$ ) provided amine 16 (200 mg, 83\%), as a colourless oil.

$\mathbf{R}_{\mathbf{f}} 0.55\left(10 \% \mathrm{MeOH} / 1 \% \mathrm{NEt}_{3} / \mathrm{CH}_{2} \mathrm{Cl}_{2}\right) ;[\alpha]_{\mathrm{D}}^{20}-21\left(c\right.$ 1.1, $\left.\mathrm{CHCl}_{3}\right)$; IR (ATR) 2931, 2855, 1560, 1454 $\mathrm{cm}^{-1} ;{ }^{1} \mathbf{H}$ NMR $\left(500 \mathrm{MHz}, \mathrm{CDCl}_{3}\right) \delta 7.60\left(1 \mathrm{H}, \mathrm{s}, \underline{\mathrm{H}}_{\mathrm{Ar}}\right), 7.33-7.27(5 \mathrm{H}, \mathrm{m}, \mathrm{Ar} \underline{\mathrm{H}}), 4.59(1 \mathrm{H}, \mathrm{dd}, J=11.0$, $\left.1.9 \mathrm{~Hz}, \underline{\mathrm{H}}_{1}\right), 4.49\left(2 \mathrm{H}, \mathrm{s}, \mathrm{OC} \underline{H}_{2} \mathrm{Ar}\right), 4.43\left(1 \mathrm{H}, \mathrm{dd}, J=14.0,3.4 \mathrm{~Hz}, \underline{\mathrm{H}}_{1 \mathrm{a}}\right), 4.19(1 \mathrm{H}, \mathrm{dd}, J=14.0,8.0 \mathrm{~Hz}$, $\left.\underline{\mathrm{H}}_{1 \mathrm{~b}}\right), 3.66-3.61\left(1 \mathrm{H}, \mathrm{m}, \underline{\mathrm{H}}_{2}\right), 3.49-3.45\left(1 \mathrm{H}, \mathrm{m}, \underline{\mathrm{H}}_{5}\right), 3.46\left(2 \mathrm{H}, \mathrm{t}, J=6.6 \mathrm{~Hz}, \underline{\mathrm{H}}_{9}\right), 3.37(2 \mathrm{H}, \mathrm{t}, J=6.6 \mathrm{~Hz}$, $\left.\underline{\mathrm{H}}_{10}\right), 3.35\left(2 \mathrm{H}, \mathrm{t}, J=6.8 \mathrm{~Hz}, \underline{\mathrm{H}}_{11}\right), 3.23-3.19\left(1 \mathrm{H}, \mathrm{m}, \underline{\mathrm{H}}_{6}\right), 2.70\left(2 \mathrm{H}\right.$, br s, $\left.\underline{\mathrm{H}}_{16}\right), 2.03-1.86\left(3 \mathrm{H}, \mathrm{m}, \underline{\mathrm{H}}_{3 \mathrm{a}}{ }^{+}\right.$ $\left.\underline{\mathrm{H}}_{4}\right)$, 1.64-1.15 (29H, m, $\left.\underline{\mathrm{H}}_{2}{ }^{\prime}-4,+\underline{\mathrm{H}}_{3 \mathrm{~b}}+\underline{\mathrm{H}}_{5}+\underline{\mathrm{H}}_{6}{ }^{\prime}-8^{\prime}+\underline{\mathrm{H}}_{7-9}+\underline{\mathrm{H}}_{12-15}\right) ;{ }^{13} \mathbf{C} \mathbf{N M R}\left(125 \mathrm{MHz}, \mathrm{CDCl}_{3}\right) \delta 150.0$, $138.8,128.5,127.8,127.6,122.4,78.4,77.8,76.2,73.3,73.0,71.0,70.9,70.5,55.1,42.1,36.4,36.2$, 
33.5, 31.8, 31.3, 31.2, 30.0, 29.9, 29.8, 28.7, 26.9, 26.2, 23.7, 23.1, 22.3, 22.2; HRMS (ESI ${ }^{+}$Calc. for $\mathrm{C}_{34} \mathrm{H}_{57} \mathrm{O}_{4} \mathrm{~N}_{4}[\mathrm{M}+\mathrm{H}]^{+}$585.4374, found 585.4358.

\subsubsection{N-(6-(4-((2S,6S)-6-((4-((2S,6S)-6-(4-(benzyloxy)butyl)tetrahydro-2H-pyran-2-yl)-1H-1,2,3-} triazol-1-yl)methyl)tetrahydro-2H-pyran-2-yl)butoxy)hexyl)benzamide 17

The general procedure was followed using benzoic acid $(4.20 \mathrm{mg}, 34.2 \mu \mathrm{mol})$. Purification by flash column chromatography (40\% EtOAc/Hexane) provided amide 17 (8.7 mg, 74\%), as a colourless oil. $\mathbf{R}_{\mathbf{f}} 0.51$ (60\% EtOAc/Hexane); $[\alpha]_{\mathrm{D}}^{20}-15$ (c 0.87, $\left.\mathrm{CHCl}_{3}\right)$; IR (ATR) 3323, 2932, 2855, 1717, 1639, 1578, $1537 \mathrm{~cm}^{-1} ;{ }^{1} \mathbf{H}$ NMR $\left(500 \mathrm{MHz}, \mathrm{CDCl}_{3}\right) \delta$ 7.76-7.75 $\left(2 \mathrm{H}, \mathrm{m}, \underline{\mathrm{H}}_{19}\right), 7.60\left(1 \mathrm{H}, \mathrm{s}, \underline{\mathrm{H}}_{\mathrm{Ar}}\right), 7.50-7.40$ $\left(3 \mathrm{H}, \mathrm{m}, \underline{\mathrm{H}}_{20}+\underline{\mathrm{H}}_{21}\right), 7.33-7.24(5 \mathrm{H}, \mathrm{m}, \mathrm{Ar} \underline{\mathrm{H}}), 6.22(1 \mathrm{H}$, br s, $\underline{\mathrm{H}}), 4.59\left(1 \mathrm{H}, \mathrm{dd}, J=11.0,1.9 \mathrm{~Hz}, \underline{\mathrm{H}}_{1}\right)$ ), $4.48\left(2 \mathrm{H}, \mathrm{s}, \mathrm{OCH}_{2} \mathrm{Ar}\right), 4.42\left(1 \mathrm{H}, \mathrm{dd}, J=14.0,3.3 \mathrm{~Hz}, \underline{\mathrm{H}}_{1 \mathrm{a}}\right), 4.19\left(1 \mathrm{H}, \mathrm{dd}, J=14.0,8.1 \mathrm{~Hz}, \underline{\mathrm{H}}_{1 \mathrm{~b}}\right), 3.65-$ $3.61\left(1 \mathrm{H}, \mathrm{m}, \underline{\mathrm{H}}_{2}\right), 3.49-3.42\left(5 \mathrm{H}, \mathrm{m}, \underline{\mathrm{H}}_{5},+\underline{\mathrm{H}}_{9},+\underline{\mathrm{H}}_{16}\right), 3.39-3.33\left(4 \mathrm{H}, \mathrm{m}, \underline{\mathrm{H}}_{10}+\underline{\mathrm{H}}_{11}\right), 3.23-3.19(1 \mathrm{H}, \mathrm{m}$, $\left.\underline{\mathrm{H}}_{6}\right), 2.02-1.83\left(3 \mathrm{H}, \mathrm{m}, \underline{\mathrm{H}}_{3 \mathrm{a}}{ }^{\prime}+\underline{\mathrm{H}}_{4}\right), 1.68-1.14\left(29 \mathrm{H}, \mathrm{m}, \underline{\mathrm{H}}_{2}{ }^{\prime}-4{ }^{\prime}+\underline{\mathrm{H}}_{3 \mathrm{~b}}+\underline{\mathrm{H}}_{5}+\underline{\mathrm{H}}_{6}{ }^{\prime}-8{ }^{\prime}+\underline{\mathrm{H}}_{7-9}+\underline{\mathrm{H}}_{12-15}\right) ;{ }^{13} \mathbf{C}$ NMR $\left(125 \mathrm{MHz}, \mathrm{CDCl}_{3}\right) \delta 167.6,149.9,138.7,134.9,131.4,128.7$ (2C), 128.5 (2C), 127.8, 127.6, 127.0, 122.4, 78.4, 77.9, 76.2, 73.3, 73.0, 70.9, 70.5, 55.1, 40.1, 36.4, 36.2, 31.8, 31.3, 29.9, 29.8 (3C), 28.7, 27.0, 26.1, 23.7, 23.1, 22.3, 22.2; HRMS (ESI ${ }^{+}$Calc. for $\mathrm{C}_{41} \mathrm{H}_{61} \mathrm{O}_{5} \mathrm{~N}_{4}[\mathrm{M}+\mathrm{H}]^{+}$689.4636, found 689.4637.

\subsubsection{N-(6-(4-((2S,6S)-6-((4-((2S,6S)-6-(4-(benzyloxy)butyl)tetrahydro-2H-pyran-2-yl)-1H-1,2,3-} triazol-1-yl)methyl)tetrahydro-2H-pyran-2-yl)butoxy)hexyl)furan-2-carboxamide 18

The general procedure was followed at a different scale. Thus, $8.00 \mathrm{mg}$ EDCI.HCl (51.3 $\mu \mathrm{mol})$ and 3.10 mg DMAP $(25.6 \mu \mathrm{mol})$ were combined with furan-2-carboxylic acid $(5.70 \mathrm{mg}, 51.3 \mu \mathrm{mol})$ followed by $15.0 \mathrm{mg}$ amine $15(25.6 \mu \mathrm{mol})$. Purification by flash column chromatography (75\% EtOAc/Hexane) provided amide 18 (12.0 $\mathrm{mg}, 69 \%)$, as a colourless oil.

$\mathbf{R}_{\mathbf{f}} 0.39$ (75\% EtOAc/Hexane); $[\alpha]_{\mathrm{D}}^{20}-16\left(c\right.$ 0.86, $\left.\mathrm{CHCl}_{3}\right)$; IR (ATR) 3314, 2932, 2857, 1651, $1593 \mathrm{~cm}^{-}$ ${ }^{1} ;{ }^{1} \mathbf{H}$ NMR $\left(500 \mathrm{MHz}, \mathrm{CDCl}_{3}\right) \delta 7.60\left(1 \mathrm{H}, \mathrm{s}, \underline{\mathrm{H}}_{\mathrm{Ar}}\right), 7.41\left(1 \mathrm{H}, \mathrm{dd}, J=1.7,0.8 \mathrm{~Hz}, \underline{\mathrm{H}}_{21}\right), 7.33-7.25(5 \mathrm{H}, \mathrm{m}$, $\operatorname{Ar} \underline{\mathrm{H}}), 7.09\left(1 \mathrm{H}, \mathrm{dd}, J=3.5,0.8 \mathrm{~Hz}, \underline{\mathrm{H}}_{19}\right), 6.48\left(1 \mathrm{H}, \mathrm{dd}, J=3.5,1.7 \mathrm{~Hz}, \underline{\mathrm{H}}_{20}\right), 6.37(1 \mathrm{H}, \mathrm{br} \mathrm{s}, \mathrm{N} \underline{\mathrm{H}}), 4.59$ $\left(1 \mathrm{H}, \mathrm{dd}, J=11.0,1.9 \mathrm{~Hz}, \underline{\mathrm{H}}_{1}\right), 4.48\left(2 \mathrm{H}, \mathrm{s}, \mathrm{OCH}_{2} \mathrm{Ar}\right), 4.43\left(1 \mathrm{H}, \mathrm{dd}, J=14.0,3.4 \mathrm{~Hz}, \underline{\mathrm{H}}_{1 \mathrm{a}}\right), 4.19(1 \mathrm{H}, \mathrm{dd}$, $\left.J=14.0,8.1 \mathrm{~Hz}, \underline{\mathrm{H}}_{1 \mathrm{~b}}\right), 3.66-3.61\left(1 \mathrm{H}, \mathrm{m}, \underline{\mathrm{H}}_{2}\right), 3.49-3.44\left(1 \mathrm{H}, \mathrm{m}, \underline{\mathrm{H}}_{5}\right), 3.46\left(2 \mathrm{H}, \mathrm{t}, J=6.6 \mathrm{~Hz}, \underline{\mathrm{H}}_{9}\right)$, 3.42$3.33\left(6 \mathrm{H}, \mathrm{m}, \underline{\mathrm{H}}_{10}+\underline{\mathrm{H}}_{11}+\underline{\mathrm{H}}_{16}\right), 3.23-3.19\left(1 \mathrm{H}, \mathrm{m}, \underline{\mathrm{H}}_{6}\right), 2.04-1.83\left(3 \mathrm{H}, \mathrm{m}, \underline{\mathrm{H}}_{3 \mathrm{a}}{ }+\underline{\mathrm{H}}_{4}\right), 1.66-1.14$ (29H, m, 
$\left.\underline{\mathrm{H}}_{2}{ }^{\prime}-4^{\prime}+\underline{\mathrm{H}}_{3 \mathrm{~b}}+\underline{\mathrm{H}}_{5}+\underline{\mathrm{H}}_{6^{\prime}-8^{\prime}}+\underline{\mathrm{H}}_{7-9}+\underline{\mathrm{H}}_{12-15}\right) ;{ }^{13} \mathbf{C} \mathbf{N M R}\left(125 \mathrm{MHz}, \mathrm{CDCl}_{3}\right) \delta 158.5,150.0,148.3,143.8$, 138.8, 128.5, 127.8, 127.6, 122.4, 114.1, 112.2, 78.4, 77.8, 76.2, 73.3, 73.0, 70.9 (2C), 70.5, 55.1, 39.2, 36.4, 36.2 31.8, 31.3, 31.2, 29.9, 29.8 (2C), 28.7, 26.9, 26.1, 23.7, 23.1, 22.8, 22.3, 22.2; HRMS (ESI $\left.{ }^{+}\right)$ Calc. for $\mathrm{C}_{39} \mathrm{H}_{59} \mathrm{O}_{6} \mathrm{~N}_{4}[\mathrm{M}+\mathrm{H}]^{+} 679.4429$, found 679.4412 .

\subsubsection{N-(6-(4-((2S,6S)-6-((4-((2S,6S)-6-(4-(benzyloxy)butyl)tetrahydro-2H-pyran-2-yl)-1H-1,2,3-} triazol-1-yl)methyl)tetrahydro-2H-pyran-2-yl)butoxy)hexyl)thiophene-2-carboxamide 19

The general procedure was followed using thiophene-2-carboxylic acid (4.40 mg, $34.2 \mu \mathrm{mol})$. Purification by flash column chromatography (60\% EtOAc/Hexane) provided amide 19 (10.0 mg, 84\%), as a colourless oil.

$\mathbf{R}_{\mathbf{f}} 0.44\left(70 \%\right.$ EtOAc/Hexane); $[\alpha]_{\mathrm{D}}^{20}-20$ (c 0.84, $\left.\mathrm{CHCl}_{3}\right)$; IR (ATR) 3321, 2932, 2855, 1628, 1545, $1512 \mathrm{~cm}^{-1} ;{ }^{1} \mathbf{H}$ NMR $\left(500 \mathrm{MHz}, \mathrm{CDCl}_{3}\right) \delta 7.60\left(1 \mathrm{H}, \mathrm{s}, \underline{\mathrm{H}}_{\mathrm{Ar}}\right), 7.49\left(1 \mathrm{H}, \mathrm{dd}, J=3.7,1.0 \mathrm{~Hz}, \underline{\mathrm{H}}_{19}\right), 7.44$ $\left(1 \mathrm{H}, \mathrm{dd}, J=4.8,1.0 \mathrm{~Hz}, \underline{\mathrm{H}}_{21}\right), 7.33-7.25(5 \mathrm{H}, \mathrm{m}, \operatorname{Ar} \underline{\mathrm{H}}), 7.06\left(1 \mathrm{H}, \mathrm{dd}, J=4.8,3.7 \mathrm{~Hz}, \underline{\mathrm{H}}_{20}\right), 6.12(1 \mathrm{H}$, br s, $\mathrm{N} \underline{\mathrm{H}}), 4.59\left(1 \mathrm{H}, \mathrm{dd}, J=10.9,1.8 \mathrm{~Hz}, \underline{\mathrm{H}}_{1}\right), 4.48\left(2 \mathrm{H}, \mathrm{s}, \mathrm{OC} \underline{H}_{2} \mathrm{Ar}\right), 4.43\left(1 \mathrm{H}, \mathrm{dd}, J=14.0,3.3 \mathrm{~Hz}, \underline{\mathrm{H}}_{1 \mathrm{a}}\right)$, $4.19\left(1 \mathrm{H}, \mathrm{dd}, J=14.0,8.1 \mathrm{~Hz}, \underline{\mathrm{H}}_{1 \mathrm{~b}}\right), 3.66-3.62\left(1 \mathrm{H}, \mathrm{m}, \underline{\mathrm{H}}_{2}\right), 3.49-3.44\left(1 \mathrm{H}, \mathrm{m}, \underline{\mathrm{H}}_{5}\right), 3.46(2 \mathrm{H}, \mathrm{t}, J=6.6$ $\left.\mathrm{Hz}, \underline{\mathrm{H}}_{9}\right), 3.42-3.32\left(6 \mathrm{H}, \mathrm{m}, \underline{\mathrm{H}}_{10}+\underline{\mathrm{H}}_{11}+\underline{\mathrm{H}}_{16}\right), 3.23-3.19\left(1 \mathrm{H}, \mathrm{m}, \underline{\mathrm{H}}_{6}\right), 2.02-1.84\left(3 \mathrm{H}, \mathrm{m}, \underline{\mathrm{H}}_{3 \mathrm{a}}{ }^{\prime}+\underline{\mathrm{H}}_{4}\right), 1.66-$ $1.13\left(29 \mathrm{H}, \mathrm{m}, \underline{\mathrm{H}}_{2}{ }^{\prime}-4{ }^{\prime}+\underline{\mathrm{H}}_{3 \mathrm{~b}}+\underline{\mathrm{H}}_{5}+\underline{\mathrm{H}}_{6}{ }^{\prime}-8^{\prime}+\underline{\mathrm{H}}_{7-9}+\underline{\mathrm{H}}_{12-15}\right) ;{ }^{13} \mathbf{C} \mathbf{N M R}\left(125 \mathrm{MHz}, \mathrm{CDCl}_{3}\right) \delta 162.0,149.9$, $139.3,138.8,129.8,128.5,127.9,127.8,127.7,127.6,122.4,78.4,77.9,76.2,73.3,73.0,70.9$ (2C), 70.5, 55.1, 40.1, 36.4, 36.2, 31.8, 31.3 (2C), 29.9, 29.8, 29.7 (2C), 28.8, 26.9, 26.1, 23.8, 23.1, 22.3, 22.2; HRMS (ESI ${ }^{+}$) Calc. for $\mathrm{C}_{39} \mathrm{H}_{59} \mathrm{O}_{5} \mathrm{~N}_{4} \mathrm{~S}[\mathrm{M}+\mathrm{H}]^{+}$695.4201, found 695.4186.

\subsubsection{N-(6-(4-((2S,6S)-6-((4-((2S,6S)-6-(4-(benzyloxy)butyl)tetrahydro-2H-pyran-2-yl)-1H-1,2,3-} triazol-1-yl)methyl)tetrahydro-2H-pyran-2-yl)butoxy)hexyl)-1 $H$-pyrrole-2-carboxamide 20

The general procedure was followed using pyrrole-2-carboxylic acid (3.80 mg, $34.2 \mu \mathrm{mol})$. Purification by flash column chromatography (60\% EtOAc/Hexane) provided amide 20 (8.0 mg, 69\%), as a colourless oil.

$\mathbf{R}_{\mathbf{f}} 0.26\left(60 \%\right.$ EtOAc/Hexane); $[\alpha]_{\mathrm{D}}^{20}-18$ (c 0.80, $\left.\mathrm{CHCl}_{3}\right)$; IR (ATR) 3238, 2932, 2855, 1717, 1626, 1562, $1526 \mathrm{~cm}^{-1} ;{ }^{1} \mathbf{H}$ NMR $\left(500 \mathrm{MHz}, \mathrm{CDCl}_{3}\right) \delta 9.43(1 \mathrm{H}$, br s, $\mathrm{NH}), 7.61\left(1 \mathrm{H}, \mathrm{s}, \underline{\mathrm{H}}_{\mathrm{Ar}}\right), 7.33-7.27(5 \mathrm{H}$, $\mathrm{m}, \operatorname{Ar} \underline{\mathrm{H}}), 6.90-6.89\left(1 \mathrm{H}, \mathrm{m}, \underline{\mathrm{H}}_{21}\right), 6.54-6.53\left(1 \mathrm{H}, \mathrm{m}, \underline{\mathrm{H}}_{19}\right), 5.96\left(1 \mathrm{H}, \mathrm{q}, J=2.9 \mathrm{~Hz}, \underline{\mathrm{H}}_{20}\right), 5.96(1 \mathrm{H}$, br s, $\mathrm{N} \underline{\mathrm{H}}), 4.59\left(1 \mathrm{H}, \mathrm{dd}, J=10.9,1.9 \mathrm{~Hz}, \underline{\mathrm{H}}_{1}\right), 4.49\left(2 \mathrm{H}, \mathrm{s}, \mathrm{OC} \underline{H}_{2} \mathrm{Ar}\right), 4.43\left(1 \mathrm{H}, \mathrm{dd}, J=14.0,3.3 \mathrm{~Hz}, \underline{\mathrm{H}}_{1 \mathrm{a}}\right)$, 
$4.19\left(1 \mathrm{H}, \mathrm{dd}, J=14.0,8.1 \mathrm{~Hz}, \underline{\mathrm{H}}_{1 \mathrm{~b}}\right), 3.93\left(3 \mathrm{H}, \mathrm{s}, \underline{\mathrm{H}}_{22}\right), 3.66-3.62\left(1 \mathrm{H}, \mathrm{m}, \underline{\mathrm{H}}_{2}\right), 3.49-3.45\left(1 \mathrm{H}, \mathrm{m}, \underline{\mathrm{H}}_{5}\right)$ ), $3.46\left(2 \mathrm{H}, \mathrm{t}, J=6.6 \mathrm{~Hz}, \underline{\mathrm{H}}_{9}\right), 3.41-3.33\left(6 \mathrm{H}, \mathrm{m}, \underline{\mathrm{H}}_{10}+\underline{\mathrm{H}}_{11}+\underline{\mathrm{H}}_{16}\right), 3.23-3.19\left(1 \mathrm{H}, \mathrm{m}, \underline{\mathrm{H}}_{6}\right), 2.02-1.83(3 \mathrm{H}$, $\left.\mathrm{m}, \underline{\mathrm{H}}_{3 \mathrm{a}}{ }^{\prime}+\underline{\mathrm{H}}_{4}\right), 1.71-1.12\left(29 \mathrm{H}, \mathrm{m}, \underline{\mathrm{H}}_{2}{ }^{\prime}-4{ }^{\prime}+\underline{\mathrm{H}}_{3 \mathrm{~b}}+\underline{\mathrm{H}}_{5}+\underline{\mathrm{H}}_{6}{ }^{\prime}-8,+\underline{\mathrm{H}}_{7-9}+\underline{\mathrm{H}}_{12-15}\right) ;{ }^{13} \mathbf{C} \mathbf{N M R}(125 \mathrm{MHz}$, $\left.\mathrm{CDCl}_{3}\right) \delta 161.1,150.0,138.8,129.7,128.5,127.8,127.6,122.4,121.3,109.9,108.5,78.4,77.9,76.2$, 73.3, 73.0, 70.9, 70.8, 70.5, 55.1, 39.4, 36.4, 36.2, 31.8, 31.3 (2C), 30.0, 29.9, 29.8, 29.7, 28.8, 26.9, 26.1, 23.8, 23.1, 22.3, 22.2; HRMS $\left(\mathrm{ESI}^{+}\right.$) Calc. for $\mathrm{C}_{39} \mathrm{H}_{59} \mathrm{O}_{5} \mathrm{~N}_{5} \mathrm{Na}[\mathrm{M}+\mathrm{Na}]^{+} 700.4408$, found 700.4395.

\subsubsection{N-(6-(4-((2S,6S)-6-((4-((2S,6S)-6-(4-(benzyloxy)butyl)tetrahydro-2H-pyran-2-yl)-1H-1,2,3-} triazol-1-yl)methyl)tetrahydro-2H-pyran-2-yl)butoxy)hexyl)-1-methyl-1 $H$-pyrrole-2-carboxamide 21

The general procedure was followed using 1-methyl-2-pyrrolecarboxylic acid (4.30 mg, $34.2 \mu \mathrm{mol})$. Purification by flash column chromatography (55\% EtOAc/Hexane) provided amide 21 (9.0 mg, 76\%), as a colourless oil.

$\mathbf{R}_{\mathbf{f}} 0.41\left(60 \%\right.$ EtOAc/Hexane); $[\alpha]_{\mathrm{D}}^{20}-17$ (c 0.60, $\left.\mathrm{CHCl}_{3}\right)$; IR (ATR) 3335, 2932, 2851, 1717, 1636, 1543, $1512 \mathrm{~cm}^{-1} ;{ }^{1} \mathbf{H}$ NMR $\left(500 \mathrm{MHz}, \mathrm{CDCl}_{3}\right) \delta 7.61\left(1 \mathrm{H}, \mathrm{s}, \underline{\mathrm{H}}_{\mathrm{Ar}}\right), 7.35-7.27(5 \mathrm{H}, \mathrm{m}, \operatorname{ArH}), 6.69(1 \mathrm{H}$, app t, $\left.J=2.0 \mathrm{~Hz}, \underline{\mathrm{H}}_{21}\right), 6.50\left(1 \mathrm{H}, \mathrm{dd}, J=3.9,1.7 \mathrm{~Hz}, \underline{\mathrm{H}}_{19}\right), 6.06\left(1 \mathrm{H}, \mathrm{dd}, J=3.9,2.4 \mathrm{~Hz}, \underline{\mathrm{H}}_{20}\right), 5.90(1 \mathrm{H}$, br s, $\mathrm{N} \underline{\mathrm{H}}), 4.59\left(1 \mathrm{H}, \mathrm{dd}, J=11.0,1.9 \mathrm{~Hz}, \underline{\mathrm{H}}_{1}\right), 4.49\left(2 \mathrm{H}, \mathrm{s}, \mathrm{OC} \underline{\mathrm{H}}_{2} \mathrm{Ar}\right), 4.43(1 \mathrm{H}, \mathrm{dd}, J=14.0,3.3 \mathrm{~Hz}$, $\left.\underline{\mathrm{H}}_{1 \mathrm{a}}\right), 4.19\left(1 \mathrm{H}, \mathrm{dd}, J=14.0,8.0 \mathrm{~Hz}, \underline{\mathrm{H}}_{1 \mathrm{~b}}\right), 3.93\left(3 \mathrm{H}, \mathrm{s}, \underline{\mathrm{H}}_{22}\right), 3.66-3.61\left(1 \mathrm{H}, \mathrm{m}, \underline{\mathrm{H}}_{2}\right), 3.49-3.45(1 \mathrm{H}, \mathrm{m}$, $\left.\underline{\mathrm{H}}_{5}\right), 3.46\left(2 \mathrm{H}, \mathrm{t}, J=6.6 \mathrm{~Hz}, \underline{\mathrm{H}}_{9}\right), 3.38-3.32\left(6 \mathrm{H}, \mathrm{m}, \underline{\mathrm{H}}_{10}+\underline{\mathrm{H}}_{11}+\underline{\mathrm{H}}_{16}\right), 3.22-3.19\left(1 \mathrm{H}, \mathrm{m}, \underline{\mathrm{H}}_{6}\right), 2.03-1.84$ $\left(3 \mathrm{H}, \mathrm{m}, \underline{\mathrm{H}}_{3 \mathrm{a}}{ }+\underline{\mathrm{H}}_{4}\right), 1.69-1.13\left(29 \mathrm{H}, \mathrm{m}, \underline{\mathrm{H}}_{2}{ }^{\prime}-4,+\underline{\mathrm{H}}_{3 \mathrm{~b}}+\underline{\mathrm{H}}_{5}+\underline{\mathrm{H}}_{6}{ }^{\prime}-{ }^{\prime}+\underline{\mathrm{H}}_{7-9}+\underline{\mathrm{H}}_{12-15}\right) ;{ }^{13} \mathbf{C}$ NMR (125 MHz, $\left.\mathrm{CDCl}_{3}\right) \delta 162.1,149.9,138.8,129.7,128.5,127.8,127.7,127.6,122.4,111.2,107.2,78.4,77.9,76.2$, 73.3, 73.0, 71.0, 70.9, 70.5, 55.1, 39.3, 36.8, 36.4, 36.2, 31.9, 31.4, 31.3, 30.0, 29.9, 29.8 (2C), 28.7, 27.0, 26.1, 23.8, 23.1, 22.3, 22.2; HRMS (ESI ${ }^{+}$) Calc. for $\mathrm{C}_{40} \mathrm{H}_{61} \mathrm{O}_{5} \mathrm{~N}_{5} \mathrm{Na}[\mathrm{M}+\mathrm{Na}]^{+}$714.4565, found 714.4549 .

\subsubsection{N-(6-(4-((2S,6S)-6-((4-((2S,6S)-6-(4-(benzyloxy)butyl)tetrahydro-2H-pyran-2-yl)-1H-1,2,3-} triazol-1-yl)methyl)tetrahydro-2H-pyran-2-yl)butoxy)hexyl)furan-3-carboxamide 22

The general procedure was followed using furan-3-carboxylic acid (3.80 mg, $34.2 \mu \mathrm{mol})$. Purification by flash column chromatography (70\% EtOAc/Hexane) provided amide 22 (10.0 $\mathrm{mg}, 86 \%$ ), as a colourless oil. 
$\mathbf{R}_{\mathbf{f}} 0.29$ (70\% EtOAc/Hexane); $[\alpha]_{\mathrm{D}}^{20}-15$ (c 0.97, $\left.\mathrm{CHCl}_{3}\right)$; IR (ATR) 3300, 2932, 2855, 1636, 1587, 1572, $1537 \mathrm{~cm}^{-1} ;{ }^{1} \mathbf{H}$ NMR $\left(500 \mathrm{MHz}, \mathrm{CDCl}_{3}\right) \delta 7.92\left(1 \mathrm{H}, \mathrm{dd}, J=1.3,0.8 \mathrm{~Hz}, \underline{\mathrm{H}}_{18}\right), 7.60\left(1 \mathrm{H}, \mathrm{s}, \underline{\mathrm{H}}_{\mathrm{Ar}}\right)$, $7.41\left(1 \mathrm{H}\right.$, app t, $\left.J=1.6 \mathrm{~Hz}, \underline{\mathrm{H}}_{21}\right), 7.34-7.25(5 \mathrm{H}, \mathrm{m}, \mathrm{Ar} \underline{\mathrm{H}}), 6.61\left(1 \mathrm{H}, \mathrm{dd}, J=1.8,0.8 \mathrm{~Hz}, \underline{\mathrm{H}}_{20}\right), 6.00(1 \mathrm{H}$, br s, $\underline{\mathrm{H}}), 4.59\left(1 \mathrm{H}, \mathrm{dd}, J=10.9,1.9 \mathrm{~Hz}, \underline{\mathrm{H}}_{1}\right), 4.48\left(2 \mathrm{H}, \mathrm{s}, \mathrm{OC} \underline{\mathrm{H}}_{2} \mathrm{Ar}\right), 4.42(1 \mathrm{H}, \mathrm{dd}, J=14.0,3.3 \mathrm{~Hz}$, $\left.\underline{\mathrm{H}}_{1 \mathrm{a}}\right), 4.18\left(1 \mathrm{H}, \mathrm{dd}, J=14.0,8.1 \mathrm{~Hz}, \underline{\mathrm{H}}_{1 \mathrm{~b}}\right), 3.66-3.61\left(1 \mathrm{H}, \mathrm{m}, \underline{\mathrm{H}}_{2}\right), 3.49-3.44\left(1 \mathrm{H}, \mathrm{m}, \underline{\mathrm{H}}_{5}\right), 3.45(2 \mathrm{H}, \mathrm{t}, J=$ $\left.6.6 \mathrm{~Hz}, \underline{\mathrm{H}}_{9}\right), 3.40-3.31\left(6 \mathrm{H}, \mathrm{m}, \underline{\mathrm{H}}_{10}+\underline{\mathrm{H}}_{11}+\underline{\mathrm{H}}_{16}\right), 3.22-3.19\left(1 \mathrm{H}, \mathrm{m}, \underline{\mathrm{H}}_{6}\right), 2.02-1.84\left(3 \mathrm{H}, \mathrm{m}, \underline{\mathrm{H}}_{3 \mathrm{a}},+\underline{\mathrm{H}}_{4}\right)$, 1.72-1.12 (29H, m, $\left.\underline{\mathrm{H}}_{2}{ }^{\prime}-{ }^{\prime}+\underline{\mathrm{H}}_{3 \mathrm{~b}}+\underline{\mathrm{H}}_{5}+\underline{\mathrm{H}}_{6^{\prime}-8^{\prime}}+\underline{\mathrm{H}}_{7-9}+\underline{\mathrm{H}}_{12-15}\right) ;{ }^{13} \mathbf{C} \mathbf{N M R}\left(125 \mathrm{MHz}, \mathrm{CDCl}_{3}\right) \delta 162.7$, $149.9,144.7,143.8,138.7,128.5,127.8,127.6,122.9,122.4,108.4,78.4,77.9,76.2,73.3,73.0,70.9$, 70.8, 70.5, 55.1, 39.6, 36.4, 36.2, 31.8, 31.3 (2C), 29.9, 29.8 (3C), 28.8, 26.9, 26.1, 23.7, 23.1, 22.4, 22.3; HRMS (ESI ${ }^{+}$) Calc. for $\mathrm{C}_{39} \mathrm{H}_{58} \mathrm{O}_{6} \mathrm{~N}_{4} \mathrm{Na}[\mathrm{M}+\mathrm{Na}]^{+}$701.4249, found 701.4229.

\subsubsection{N-(6-(4-((2S,6S)-6-((4-((2S,6S)-6-(4-(benzyloxy)butyl)tetrahydro-2H-pyran-2-yl)-1H-1,2,3-} triazol-1-yl)methyl)tetrahydro-2H-pyran-2-yl)butoxy)hexyl)thiophene-3-carboxamide 23

The general procedure was followed using thiophene-3-carboxylic acid (4.40 mg, $34.2 \mu \mathrm{mol})$. Purification by flash column chromatography (60\% EtOAc/Hexane) provided amide 23 (11.0 mg, 92\%), as a colourless oil.

$\mathbf{R}_{\mathbf{f}} 0.38$ (70\% EtOAc/Hexane); $[\alpha]_{\mathrm{D}}^{20}-13$ (c 1.1, $\left.\mathrm{CHCl}_{3}\right)$; IR (ATR) 3318, 2932, 2855, 1715, 1634, 1545 , $1508 \mathrm{~cm}^{-1} ;{ }^{1} \mathbf{H}$ NMR $\left(500 \mathrm{MHz}, \mathrm{CDCl}_{3}\right) \delta 7.85\left(1 \mathrm{H}, \mathrm{dd}, J=2.9,1.2 \mathrm{~Hz}, \underline{\mathrm{H}}_{18}\right), 7.61\left(1 \mathrm{H}, \mathrm{s}, \underline{\mathrm{H}}_{\mathrm{Ar}}\right), 7.38$ $\left(1 \mathrm{H}, \mathrm{dd}, J=5.0,1.2 \mathrm{~Hz}, \underline{\mathrm{H}}_{21}\right), 7.33-7.25\left(6 \mathrm{H}, \mathrm{m}, \underline{\mathrm{H}}_{20}+\mathrm{ArH}\right), 6.11(1 \mathrm{H}, \mathrm{br} \mathrm{s}, \mathrm{N} \underline{\mathrm{H}}), 4.59$ (1H, dd, $J=10.9$, $\left.1.8 \mathrm{~Hz}, \underline{\mathrm{H}}_{1}\right), 4.48\left(2 \mathrm{H}, \mathrm{s}, \mathrm{OC} \underline{\mathrm{H}}_{2} \mathrm{Ar}\right), 4.43\left(1 \mathrm{H}, \mathrm{dd}, J=14.0,3.3 \mathrm{~Hz}, \underline{\mathrm{H}}_{1 \mathrm{a}}\right), 4.19(1 \mathrm{H}, \mathrm{dd}, J=14.0,8.1 \mathrm{~Hz}$, $\left.\underline{\mathrm{H}}_{1 \mathrm{~b}}\right), 3.66-3.62\left(1 \mathrm{H}, \mathrm{m}, \underline{\mathrm{H}}_{2}\right), 3.49-3.44\left(1 \mathrm{H}, \mathrm{m}, \underline{\mathrm{H}}_{5}\right), 3.46\left(2 \mathrm{H}, \mathrm{t}, J=6.6 \mathrm{~Hz}, \underline{\mathrm{H}}_{9}\right), 3.42-3.32\left(6 \mathrm{H}, \mathrm{m}, \underline{\mathrm{H}}_{10}\right.$ $\left.+\underline{\mathrm{H}}_{11}+\underline{\mathrm{H}}_{16}\right), 3.23-3.19\left(1 \mathrm{H}, \mathrm{m}, \underline{\mathrm{H}}_{6}\right), 2.02-1.86\left(3 \mathrm{H}, \mathrm{m}, \underline{\mathrm{H}}_{3 \mathrm{a}}{ }^{\prime}+\underline{\mathrm{H}}_{4}\right), 1.69-1.12\left(29 \mathrm{H}, \mathrm{m}, \underline{\mathrm{H}}_{2}{ }^{\prime}-4{ }^{\prime}+\underline{\mathrm{H}}_{3 \mathrm{~b}}+\underline{\mathrm{H}}_{5}+\right.$ $\left.\underline{\mathrm{H}}_{6}{ }^{\prime}-8,+\underline{\mathrm{H}}_{7-9}+\underline{\mathrm{H}}_{12-15}\right) ;{ }^{13} \mathbf{C} \mathbf{N M R}\left(125 \mathrm{MHz}, \mathrm{CDCl}_{3}\right) \delta 163.2,149.9,138.8,137.9,128.5,128.1,127.8$, $127.6,126.5,126.1,122.5,78.4,77.9,76.2,73.3,73.0,70.9,70.8,70.5,55.1,39.9,36.4,36.2,31.8$, 31.3 (2C), 29.9, 29.8 (2C), 29.7, 28.8, 26.9, 26.1, 23.8, 23.1, 22.3, 22.2; HRMS (ESI ${ }^{+}$) Calc. for $\mathrm{C}_{39} \mathrm{H}_{58} \mathrm{O}_{5} \mathrm{~N}_{4} \mathrm{SNa}[\mathrm{M}+\mathrm{Na}]^{+}$717.4020, found 717.4008.

\subsubsection{N-(6-(4-((2S,6S)-6-((4-((2S,6S)-6-(4-(benzyloxy)butyl)tetrahydro-2H-pyran-2-yl)-1H-1,2,3-} triazol-1-yl)methyl)tetrahydro-2H-pyran-2-yl)butoxy)hexyl)thiazole-4-carboxamide 24 
The general procedure was followed using 1,3-thiazole-4-carboxylic acid (4.40 mg, $34.2 \mu \mathrm{mol}$ ). Purification by flash column chromatography (75\% EtOAc/Hexane) provided amide 24 (9.8 mg, 82\%), as a colourless oil.

$\mathbf{R}_{\mathbf{f}} 0.23\left(70 \%\right.$ EtOAc/Hexane); $[\alpha]_{\mathrm{D}}^{20}-19$ (c 0.72, $\left.\mathrm{CHCl}_{3}\right)$; IR (ATR) 3361, 3064, 2932, 2851, 1647, $1541 \mathrm{~cm}^{-1} ;{ }^{1} \mathbf{H}$ NMR $\left(500 \mathrm{MHz}, \mathrm{CDCl}_{3}\right) \delta 8.73\left(1 \mathrm{H}, \mathrm{d}, J=2.1 \mathrm{~Hz}, \underline{\mathrm{H}}_{20}\right), 8.15\left(1 \mathrm{H}, \mathrm{d}, J=2.1 \mathrm{~Hz}, \underline{\mathrm{H}}_{19}\right)$, $7.60\left(1 \mathrm{H}, \mathrm{s}, \underline{\mathrm{H}}_{\mathrm{Ar}}\right), 7.39(1 \mathrm{H}, \mathrm{br} \mathrm{s}, \mathrm{N} \underline{\mathrm{H}}), 7.35-7.24(5 \mathrm{H}, \mathrm{m}, \mathrm{Ar} \underline{\mathrm{H}}), 4.59\left(1 \mathrm{H}, \mathrm{dd}, J=10.9,1.8 \mathrm{~Hz}, \underline{\mathrm{H}}_{1}\right.$ ) $), 4.48$ $\left(2 \mathrm{H}, \mathrm{s}, \mathrm{OC} \underline{\mathrm{H}}_{2} \mathrm{Ar}\right), 4.43\left(1 \mathrm{H}, \mathrm{dd}, J=14.0,3.4 \mathrm{~Hz}, \underline{\mathrm{H}}_{1 \mathrm{a}}\right), 4.19\left(1 \mathrm{H}, \mathrm{dd}, J=14.0,8.0 \mathrm{~Hz}, \underline{\mathrm{H}}_{1 \mathrm{~b}}\right), 3.66-3.61$ $\left(1 \mathrm{H}, \mathrm{m}, \underline{\mathrm{H}}_{2}\right), 3.49-3.42\left(5 \mathrm{H}, \mathrm{m}, \underline{\mathrm{H}}_{16}+\underline{\mathrm{H}}_{5},+\underline{\mathrm{H}}_{9}\right), 3.38-3.34\left(4 \mathrm{H}, \mathrm{m}, \underline{\mathrm{H}}_{10}+\underline{\mathrm{H}}_{11}\right), 3.23-3.19\left(1 \mathrm{H}, \mathrm{m}, \underline{\mathrm{H}}_{6}\right)$, 2.02-1.83 (3H, m, $\left.\underline{\mathrm{H}}_{3 \mathrm{a}}{ }^{\prime}+\underline{\mathrm{H}}_{4}\right)$, 1.66-1.12 (29H, m, $\left.\underline{\mathrm{H}}_{2}{ }^{\prime}-4,+\underline{\mathrm{H}}_{3 \mathrm{~b}}+\underline{\mathrm{H}}_{5}+\underline{\mathrm{H}}_{6}{ }^{\prime}-8{ }^{\prime}+\underline{\mathrm{H}}_{7-9}+\underline{\mathrm{H}}_{12-15}\right) ;{ }^{13} \mathbf{C} \mathbf{N M R}$ $\left(125 \mathrm{MHz}, \mathrm{CDCl}_{3}\right) \delta 161.0,152.7,151.4,150.0,138.8,128.5,127.8,127.6,123.1,122.4,78.4,77.8$, 76.2, 73.3, 73.0, 71.0, 70.9, 70.5, 55.1, 39.4, 36.4, 36.2, 31.8, 31.3, 31.2, 29.9, 29.8 (2C), 29.7, 28.7, 27.0, 26.1, 23.7, 23.1, 22.3, 22.2; HRMS (ESI ${ }^{+}$) Calc. for $\mathrm{C}_{38} \mathrm{H}_{58} \mathrm{O}_{5} \mathrm{~N}_{5} \mathrm{~S}[\mathrm{M}+\mathrm{H}]^{+}$696.4153, found 696.4126.

\subsubsection{N-(6-(4-((2S,6S)-6-((4-((2S,6S)-6-(4-(benzyloxy)butyl)tetrahydro-2H-pyran-2-yl)-1H-1,2,3-} triazol-1-yl)methyl)tetrahydro-2H-pyran-2-yl)butoxy)hexyl)oxazole-4-carboxamide 25

The general procedure was followed using 1,3-oxazole-4-carboxylic acid (3.90 mg, $34.2 \mu \mathrm{mol})$ and DMF (2 mL) as solvent. Purification by flash column chromatography (75\% EtOAc/Hexane) provided amide 25 (5.5 mg, 47\%), as a colourless oil.

$\mathbf{R}_{\mathbf{f}} 0.26$ (75\% EtOAc/Hexane); $[\alpha]_{\mathrm{D}}^{20}-21$ (c 0.50, $\left.\mathrm{CHCl}_{3}\right)$; IR (ATR) 3335, 2934, 2857, 1661, 1595, $1514 \mathrm{~cm}^{-1} ;{ }^{1} \mathbf{H}$ NMR $\left(400 \mathrm{MHz}, \mathrm{CDCl}_{3}\right) \delta 8.21\left(1 \mathrm{H}, \mathrm{d}, J=1.0 \mathrm{~Hz}, \underline{\mathrm{H}}_{19}\right), 7.84\left(1 \mathrm{H}, \mathrm{d}, J=1.0 \mathrm{~Hz}, \underline{\mathrm{H}}_{20}\right)$, $7.60\left(1 \mathrm{H}, \mathrm{s}, \underline{\mathrm{H}}_{\mathrm{Ar}}\right), 7.35-7.24(5 \mathrm{H}, \mathrm{m}, \mathrm{Ar} \underline{\mathrm{H}}), 6.92(1 \mathrm{H}, \mathrm{br} \mathrm{s}, \mathrm{NH}), 4.59\left(1 \mathrm{H}, \mathrm{dd}, J=10.9,1.9 \mathrm{~Hz}, \underline{\mathrm{H}}_{1},\right), 4.49$ $\left(2 \mathrm{H}, \mathrm{s}, \mathrm{OC}_{2} \mathrm{Ar}\right), 4.43\left(1 \mathrm{H}, \mathrm{dd}, J=14.0,3.4 \mathrm{~Hz}, \underline{\mathrm{H}}_{1 \mathrm{a}}\right), 4.19\left(1 \mathrm{H}, \mathrm{dd}, J=14.0,8.0 \mathrm{~Hz}, \underline{\mathrm{H}}_{1 \mathrm{~b}}\right), 3.67-3.61$ $\left(1 \mathrm{H}, \mathrm{m}, \underline{\mathrm{H}}_{2}\right), 3.50-3.44\left(3 \mathrm{H}, \mathrm{m}, \underline{\mathrm{H}}_{5},+\underline{\mathrm{H}}_{9}\right), 3.43-3.33\left(6 \mathrm{H}, \mathrm{m}, \underline{\mathrm{H}}_{10}+\underline{\mathrm{H}}_{11}+\underline{\mathrm{H}}_{16}\right), 3.24-3.19\left(1 \mathrm{H}, \mathrm{m}, \underline{\mathrm{H}}_{6}\right)$, 2.03-1.83 (3H, m, $\left.\underline{\mathrm{H}}_{3 \mathrm{a}}{ }^{\prime}+\underline{\mathrm{H}}_{4}\right), 1.63-1.14\left(29 \mathrm{H}, \mathrm{m}, \underline{\mathrm{H}}_{2}{ }^{\prime}-4,+\underline{\mathrm{H}}_{3 \mathrm{~b}}+\underline{\mathrm{H}}_{5}+\underline{\mathrm{H}}_{6}{ }^{\prime}-8,+\underline{\mathrm{H}}_{7-9}+\underline{\mathrm{H}}_{12-15}\right) ;{ }^{13} \mathbf{C} \mathbf{N M R}$ $\left(100 \mathrm{MHz}, \mathrm{CDCl}_{3}\right) \delta 160.3,150.6,150.0,141.3,138.8,136.2,128.5,127.8,127.6,122.4,78.4,77.9$, 76.2, 73.3, 73.0, 71.0 (2C), 70.5, 55.1, 39.1, 36.4, 36.2, 31.9, 31.4, 31.3, 29.9, 29.8, 29.7, 28.8 (2C), 26.9, 26.1, 23.8, 23.1, 22.3, 22.3; HRMS (ESI ${ }^{+}$Calc. for $\mathrm{C}_{38} \mathrm{H}_{57} \mathrm{O}_{6} \mathrm{~N}_{5} \mathrm{Na}[\mathrm{M}+\mathrm{Na}]^{+}$702.4201, found 702.4182.

4.2.14 N-(6-(4-((2S,6S)-6-((4-((2S,6S)-6-(4-(benzyloxy)butyl)tetrahydro-2H-pyran-2-yl)-1H-1,2,3triazol-1-yl)methyl)tetrahydro-2H-pyran-2-yl)butoxy)hexyl)-2-methyloxazole-4-carboxamide 26 
The general procedure was followed using 2-methyl-1,3-oxazole-4-carboxylic acid (4.30 mg, 34.2 $\mu \mathrm{mol})$. Purification by flash column chromatography (75\% EtOAc/Hexane) provided amide 26 (9.6 mg, $81 \%$ ), as a colourless oil.

$\mathbf{R}_{\mathbf{f}} 0.23\left(75 \%\right.$ EtOAc/Hexane); $[\alpha]_{\mathrm{D}}^{20}-15$ (c 0.96, $\left.\mathrm{CHCl}_{3}\right)$; IR (ATR) 3362, 2932, 2855, 1668, 1647 , 1607, $1518 \mathrm{~cm}^{-1}$; ${ }^{1} \mathbf{H}$ NMR (400 MHz, $\left.\mathrm{CDCl}_{3}\right) \delta 8.05\left(1 \mathrm{H}, \mathrm{s}, \underline{\mathrm{H}}_{19}\right), 7.60\left(1 \mathrm{H}, \mathrm{s}, \underline{\mathrm{H}}_{\mathrm{Ar}}\right), 7.35-7.24(5 \mathrm{H}, \mathrm{m}$, $\operatorname{Ar} \underline{\mathrm{H}}), 6.86(1 \mathrm{H}, \mathrm{br} \mathrm{s}, \mathrm{NH}), 4.59\left(1 \mathrm{H}, \mathrm{dd}, J=10.8,1.8 \mathrm{~Hz}, \underline{\mathrm{H}}_{1}\right), 4.48\left(2 \mathrm{H}, \mathrm{s}, \mathrm{OC}_{2} \mathrm{Ar}\right), 4.43(1 \mathrm{H}, \mathrm{dd}, J=$ 14.0, $\left.3.4 \mathrm{~Hz}, \underline{\mathrm{H}}_{1 \mathrm{a}}\right), 4.19\left(1 \mathrm{H}, \mathrm{dd}, J=14.0,8.0 \mathrm{~Hz}, \underline{\mathrm{H}}_{1 \mathrm{~b}}\right), 3.66-3.61\left(1 \mathrm{H}, \mathrm{m}, \underline{\mathrm{H}}_{2}\right), 3.50-3.44\left(1 \mathrm{H}, \mathrm{m}, \underline{\mathrm{H}}_{5}\right)$ ), $3.46\left(1 \mathrm{H}, \mathrm{t}, J=6.6 \mathrm{~Hz}, \underline{\mathrm{H}}_{9}\right), 3.41-3.34\left(6 \mathrm{H}, \mathrm{m}, \underline{\mathrm{H}}_{10}+\underline{\mathrm{H}}_{11}+\underline{\mathrm{H}}_{16}\right), 3.24-3.19\left(1 \mathrm{H}, \mathrm{m}, \underline{\mathrm{H}}_{6}\right), 2.46$ (3H, s, $\left.\underline{\mathrm{H}}_{21}\right)$, 2.04-1.83 (3H, m, $\left.\underline{\mathrm{H}}_{3 \mathrm{a}}{ }^{\prime}+\underline{\mathrm{H}}_{4}\right)$, 1.66-1.12 (29H, m, $\left.\underline{\mathrm{H}}_{2}{ }^{\prime}-4,+\underline{\mathrm{H}}_{3 \mathrm{~b}}+\underline{\mathrm{H}}_{5}+\underline{\mathrm{H}}_{6}{ }^{\prime}-8^{\prime}+\underline{\mathrm{H}}_{7-9}+\underline{\mathrm{H}}_{12-15}\right) ;{ }^{13} \mathbf{C}$ NMR $\left(125 \mathrm{MHz}, \mathrm{CDCl}_{3}\right) \delta 161.4,160.8,150.0,140.8,138.8,136.4,128.5,127.8,127.6,122.4,78.4$, 77.8, 76.2, 73.3, 73.0, 71.0, 70.9, 70.5, 55.1, 39.1, 36.4, 36.2, 31.8, 31.3, 31.2, 29.9, 29.8 (2C), 29.7, 28.7, 26.9, 26.1, 23.7, 23.1, 22.3, 22.2, 14.0; HRMS (ESI ${ }^{+}$) Calc. for $\mathrm{C}_{39} \mathrm{H}_{60} \mathrm{O}_{6} \mathrm{~N}_{5}[\mathrm{M}+\mathrm{H}]^{+} 694.4538$, found 694.4514 .

\subsubsection{N-(6-(4-((2S,6S)-6-((4-((2S,6S)-6-(4-(benzyloxy)butyl)tetrahydro-2H-pyran-2-yl)-1H-1,2,3-} triazol-1-yl)methyl)tetrahydro-2H-pyran-2-yl)butoxy)hexyl)-1-methyl-1 $H$-pyrazole-5carboxamide 27

The general procedure was followed at a different scale. Thus, $8.00 \mathrm{mg}$ EDCI.HCl (51.3 $\mu \mathrm{mol})$ and 3.10 mg DMAP $(25.6 \mu \mathrm{mol})$ were combined with 2-methyl-2H-pyrazole-3-carboxylic acid (6.50 mg, 51.3 $\mu \mathrm{mol})$ followed by $15.0 \mathrm{mg}$ amine $15(25.6 \mu \mathrm{mol})$. Purification by flash column chromatography $(75 \%$ EtOAc/Hexane) provided amide $27(12.0 \mathrm{mg}, 68 \%)$, as a colourless oil.

$\mathbf{R}_{\mathbf{f}} 0.29$ (75\% EtOAc/Hexane); $[\alpha]_{\mathrm{D}}^{20}-13$ (c 0.45, $\left.\mathrm{CHCl}_{3}\right)$; IR (ATR) 3323, 2934, 2857, 1724, 1661, $1543 \mathrm{~cm}^{-1} ;{ }^{1} \mathbf{H}$ NMR (500 MHz, $\left.\mathrm{CDCl}_{3}\right) \delta 7.60\left(1 \mathrm{H}, \mathrm{s}, \underline{\mathrm{H}}_{\mathrm{Ar}}\right), 7.42\left(1 \mathrm{H}, \mathrm{d}, J=2.1 \mathrm{~Hz}, \underline{\mathrm{H}}_{19}\right), 7.33-7.27$ $(5 \mathrm{H}, \mathrm{m}, \mathrm{Ar} \underline{\mathrm{H}}), 6.49\left(1 \mathrm{H}, \mathrm{d}, J=2.1 \mathrm{~Hz}, \underline{\mathrm{H}}_{20}\right), 6.18(1 \mathrm{H}$, br s, $\underline{\mathrm{H}}), 4.59\left(1 \mathrm{H}, \mathrm{dd}, J=11.0,1.9 \mathrm{~Hz}, \underline{\mathrm{H}}_{1}\right)$, $4.48\left(2 \mathrm{H}, \mathrm{s}, \mathrm{OCH}_{2} \mathrm{Ar}\right), 4.42\left(1 \mathrm{H}, \mathrm{dd}, J=14.0,3.3 \mathrm{~Hz}, \underline{\mathrm{H}}_{1 \mathrm{a}}\right), 4.19\left(1 \mathrm{H}, \mathrm{dd}, J=14.0,8.1 \mathrm{~Hz}, \underline{\mathrm{H}}_{1 \mathrm{~b}}\right), 4.17$ $\left(3 \mathrm{H}, \mathrm{s}, \underline{\mathrm{H}}_{21}\right), 3.66-3.62\left(1 \mathrm{H}, \mathrm{m}, \underline{\mathrm{H}}_{2}\right), 3.49-3.44\left(1 \mathrm{H}, \mathrm{m}, \underline{\mathrm{H}}_{5}\right), 3.46\left(2 \mathrm{H}, \mathrm{t}, J=6.6 \mathrm{~Hz}, \underline{\mathrm{H}}_{9}\right), 3.39-3.33(6 \mathrm{H}$, $\left.\mathrm{m}, \underline{\mathrm{H}}_{10}+\underline{\mathrm{H}}_{11}+\underline{\mathrm{H}}_{16}\right), 3.22-3.19\left(1 \mathrm{H}, \mathrm{m}, \underline{\mathrm{H}}_{6}\right), 2.04-1.91\left(3 \mathrm{H}, \mathrm{m}, \underline{\mathrm{H}}_{3 \mathrm{a}}, \underline{\mathrm{H}}_{4}\right), 1.69-1.15\left(29 \mathrm{H}, \mathrm{m}, \underline{\mathrm{H}}_{2^{\prime}-4^{\prime}}+\underline{\mathrm{H}}_{3 \mathrm{~b}}\right.$ $\left.+\underline{\mathrm{H}}_{5}+\underline{\mathrm{H}}_{6}{ }^{\prime-8}{ }^{\prime}+\underline{\mathrm{H}}_{7-9}+\underline{\mathrm{H}}_{12-15}\right) ;{ }^{13} \mathbf{C} \mathbf{N M R}\left(125 \mathrm{MHz}, \mathrm{CDCl}_{3}\right) \delta 160.1,150.0,138.7,137.7,135.6,128.5$, $127.8,127.6,122.4,106.2,78.4,77.9,76.2,73.3,73.0,70.9,70.8,70.5,55.1,39.6,39.4,36.4,36.2$, 
31.8, 31.3 (2C), 29.9, 29.8, 29.7 (2C), 28.8, 26.9, 26.1, 23.7, 23.1, 22.3, 22.2; HRMS (ESI ${ }^{+}$Calc. for $\mathrm{C}_{39} \mathrm{H}_{61} \mathrm{O}_{5} \mathrm{~N}_{6}[\mathrm{M}+\mathrm{H}]^{+}$693.4698, found 693.4681.

\subsubsection{N-(6-(4-((2S,6S)-6-((4-((2S,6S)-6-(4-(benzyloxy)butyl)tetrahydro-2H-pyran-2-yl)-1H-1,2,3-} triazol-1-yl)methyl)tetrahydro-2H-pyran-2-yl)butoxy)hexyl)-5-methylfuran-2-carboxamide 28

The general procedure was followed using 5-methyl-furan-2-carboxylic acid (4.30 mg, $34.2 \mu \mathrm{mol})$. Purification by flash column chromatography (75\% EtOAc/Hexane) provided amide 28 (8.1 mg, 67\%), as a colourless oil.

$\mathbf{R}_{\mathbf{f}} 0.34$ (75\% EtOAc/Hexane); $[\alpha]_{\mathrm{D}}^{20}-17\left(c\right.$ 0.81, $\left.\mathrm{CHCl}_{3}\right)$; IR (ATR) 3298, 2932, 2857, 1717, 1647, 1609, $1555 \mathrm{~cm}^{-1} ;{ }^{1} \mathbf{H}$ NMR $\left(400 \mathrm{MHz}, \mathrm{CDCl}_{3}\right) \delta 7.60\left(1 \mathrm{H}, \mathrm{s}, \underline{\mathrm{H}}_{\mathrm{Ar}}\right), 7.33-7.24(5 \mathrm{H}, \mathrm{m}, \mathrm{Ar} \underline{\mathrm{H}}), 6.98(1 \mathrm{H}, \mathrm{d}$, $\left.J=3.3 \mathrm{~Hz}, \underline{\mathrm{H}}_{19}\right), 6.27(1 \mathrm{H}$, br s, $\underline{\mathrm{H}}), 6.08\left(1 \mathrm{H}, \mathrm{d}, J=3.3 \mathrm{~Hz}, \underline{\mathrm{H}}_{20}\right), 4.59\left(1 \mathrm{H}, \mathrm{dd}, J=10.9,1.9 \mathrm{~Hz}, \underline{\mathrm{H}}_{1}\right)$, $4.49\left(2 \mathrm{H}, \mathrm{s}, \mathrm{OCH}_{2} \mathrm{Ar}\right), 4.43\left(1 \mathrm{H}, \mathrm{dd}, J=14.0,3.4 \mathrm{~Hz}, \underline{\mathrm{H}}_{1 \mathrm{a}}\right), 4.19\left(1 \mathrm{H}, \mathrm{dd}, J=14.0,8.0 \mathrm{~Hz}, \underline{\mathrm{H}}_{1 \mathrm{~b}}\right), 3.66-$ $3.61\left(1 \mathrm{H}, \mathrm{m}, \underline{\mathrm{H}}_{2}\right), 3.50-3.44\left(1 \mathrm{H}, \mathrm{m}, \underline{\mathrm{H}}_{5}\right), 3.46\left(2 \mathrm{H}, \mathrm{t}, J=6.6 \mathrm{~Hz}, \underline{\mathrm{H}}_{9}\right), 3.41-3.34\left(6 \mathrm{H}, \mathrm{m}, \underline{\mathrm{H}}_{10}+\underline{\mathrm{H}}_{11}+\right.$ $\left.\underline{\mathrm{H}}_{16}\right), 3.23-3.19\left(1 \mathrm{H}, \mathrm{m}, \underline{\mathrm{H}}_{6}\right), 2.33\left(3 \mathrm{H}, \mathrm{s}, \underline{\mathrm{H}}_{22}\right), 2.03-1.83\left(3 \mathrm{H}, \mathrm{m}, \underline{\mathrm{H}}_{3 \mathrm{a}^{\prime}}+\underline{\mathrm{H}}_{4}\right), 1.64-1.12\left(29 \mathrm{H}, \mathrm{m}, \underline{\mathrm{H}}_{2^{\prime}-4^{\prime}},+\right.$ $\left.\underline{\mathrm{H}}_{3 \mathrm{~b}}+\underline{\mathrm{H}}_{5}+\underline{\mathrm{H}}_{6-8},+\underline{\mathrm{H}}_{7-9}+\underline{\mathrm{H}}_{12-15}\right) ;{ }^{13} \mathbf{C} \mathbf{N M R}\left(100 \mathrm{MHz}, \mathrm{CDCl}_{3}\right) \delta$ 158.7, 154.3, 150.0, 146.7, 138.8, 128.5, $127.8,127.6,122.4,115.3,108.6,78.4,77.9,76.2,73.3,73.0,71.0,70.9,70.5,55.1,39.1,36.4,36.2$, 31.9, 31.4, 31.3, 30.0, 29.9, 29.8 (2C), 28.8, 26.9, 26.1, 23.8, 23.1, 22.4, 22.3, 14.0; HRMS (ESI ${ }^{+}$) Calc. for $\mathrm{C}_{40} \mathrm{H}_{60} \mathrm{O}_{6} \mathrm{~N}_{4} \mathrm{Na}[\mathrm{M}+\mathrm{Na}]^{+} 715.4405$, found 715.4389 .

\subsubsection{N-(6-(4-((2S,6S)-6-((4-((2S,6S)-6-(4-(benzyloxy)butyl)tetrahydro-2H-pyran-2-yl)-1H-1,2,3-} triazol-1-yl)methyl)tetrahydro-2H-pyran-2-yl)butoxy)hexyl)-3-methylfuran-2-carboxamide 29

The general procedure was followed using 3-methyl-furan-2-carboxylic acid (4.30 mg, $34.2 \mu \mathrm{mol})$. Purification by flash column chromatography (50\% EtOAc/Hexane) provided amide 29 (10.6 mg, 90\%), as a colourless oil.

$\mathbf{R}_{\mathbf{f}} 0.41$ (60\% EtOAc/Hexane); $[\alpha]_{\mathrm{D}}^{20}-15$ (c 0.96, $\left.\mathrm{CHCl}_{3}\right)$; IR (ATR) 2916, 2849, 1734, 1651, 1612, $1526 \mathrm{~cm}^{-1}$; ${ }^{1} \mathbf{H}$ NMR $\left(400 \mathrm{MHz}, \mathrm{CDCl}_{3}\right) \delta 7.60\left(1 \mathrm{H}, \mathrm{s}, \underline{\mathrm{H}}_{\mathrm{Ar}}\right), 7.33-7.25\left(6 \mathrm{H}, \mathrm{m}, \underline{\mathrm{H}}_{22}+\mathrm{Ar} \underline{\mathrm{H}}\right), 6.33(1 \mathrm{H}, \mathrm{br}$ $\mathrm{s}, \mathrm{N} \underline{\mathrm{H}}), 6.31\left(1 \mathrm{H}, \mathrm{d}, J=1.6 \mathrm{~Hz}, \underline{\mathrm{H}}_{21}\right), 4.59\left(1 \mathrm{H}, \mathrm{dd}, J=10.8,1.9 \mathrm{~Hz}, \underline{\mathrm{H}}_{1}\right), 4.48\left(2 \mathrm{H}, \mathrm{s}, \mathrm{OC} \underline{\mathrm{H}}_{2} \mathrm{Ar}\right), 4.43$ $\left(1 \mathrm{H}, \mathrm{dd}, J=14.0,3.3 \mathrm{~Hz}, \underline{\mathrm{H}}_{1 \mathrm{a}}\right), 4.19\left(1 \mathrm{H}, \mathrm{dd}, J=14.0,8.0 \mathrm{~Hz}, \underline{\mathrm{H}}_{1 \mathrm{~b}}\right), 3.67-3.60\left(1 \mathrm{H}, \mathrm{m}_{2} \underline{\mathrm{H}}_{2}\right), 3.50-3.44$ $\left(1 \mathrm{H}, \mathrm{m}, \underline{\mathrm{H}}_{5}\right), 3.46\left(2 \mathrm{H}, \mathrm{t}, J=6.6 \mathrm{~Hz}, \underline{\mathrm{H}}_{9}\right), 3.40-3.33\left(6 \mathrm{H}, \mathrm{m}, \underline{\mathrm{H}}_{10}+\underline{\mathrm{H}}_{11}+\underline{\mathrm{H}}_{16}\right), 3.23-3.18\left(1 \mathrm{H}, \mathrm{m}, \underline{\mathrm{H}}_{6}\right)$, $2.39\left(3 \mathrm{H}, \mathrm{s}, \underline{\mathrm{H}}_{20}\right), 2.04-1.83\left(3 \mathrm{H}, \mathrm{m}, \underline{\mathrm{H}}_{3 \mathrm{a}^{\mathrm{a}}}+\underline{\mathrm{H}}_{4}\right), 1.67-1.12\left(29 \mathrm{H}, \mathrm{m}, \underline{\mathrm{H}}_{2^{\prime}-4},+\underline{\mathrm{H}}_{3 \mathrm{~b}}+\underline{\mathrm{H}}_{5}+\underline{\mathrm{H}}_{6^{\prime}-8^{\prime}}+\underline{\mathrm{H}}_{7-9}+\underline{\mathrm{H}}_{12-}\right.$ 
$\left.{ }_{15}\right) ;{ }^{13} \mathrm{C}$ NMR $\left(100 \mathrm{MHz}, \mathrm{CDCl}_{3}\right) \delta 159.8,150.0,142.5,142.1,138.8,128.5,127.8,127.6,127.3,122.4$, 115.5, 78.4, 77.9, 76.2, 73.3, 73.0, 71.0, 70.9, 70.5, 55.1, 38.9, 36.4, 36.2, 31.9, 31.4, 31.3, 29.9 (2C), 29.8 (2C), 28.8, 27.0, 26.1, 23.8, 23.1, 22.4, 22.3, 11.2; HRMS (ESI ${ }^{+}$) Calc. for $\mathrm{C}_{40} \mathrm{H}_{60} \mathrm{O}_{6} \mathrm{~N}_{4} \mathrm{Na}$ $[\mathrm{M}+\mathrm{Na}]^{+} 715.4405$, found 715.4388 .

\subsubsection{8 $N-(6-(4-((2 S, 6 S)-6-((4-((2 S, 6 S)-6-(4-(b e n z y l o x y) b u t y l) t e t r a h y d r o-2 H-p y r a n-2-y l)-1 H-1,2,3-$} triazol-1-yl)methyl)tetrahydro-2H-pyran-2-yl)butoxy)hexyl)-4,5-dimethylfuran-2-carboxamide 30

The general procedure was followed using 4,5-dimethylfuran-2-carboxylic acid (4.80 mg, $34.2 \mu \mathrm{mol})$. Purification by flash column chromatography (60\% EtOAc/Hexane) provided amide 30 (7.6 mg, 63\%), as a colourless oil.

$\mathbf{R}_{\mathbf{f}} 0.29\left(60 \%\right.$ EtOAc/Petrol); $[\alpha]_{\mathrm{D}}^{20}-19\left(c\right.$ 0.73, $\left.\mathrm{CHCl}_{3}\right)$; IR (ATR) 3310, 2932, 2857, 1717, 1645, 1564 $\mathrm{cm}^{-1} ;{ }^{1} \mathbf{H}$ NMR $\left(400 \mathrm{MHz}, \mathrm{CDCl}_{3}\right) \delta 7.60\left(1 \mathrm{H}, \mathrm{s}, \underline{\mathrm{H}}_{\mathrm{Ar}}\right), 7.33-7.28(5 \mathrm{H}, \mathrm{m}, \mathrm{Ar} \underline{\mathrm{H}}), 6.86(1 \mathrm{H}, \mathrm{d}, J=3.3 \mathrm{~Hz}$, $\left.\underline{\mathrm{H}}_{19}\right), 6.23(1 \mathrm{H}$, br s, $\underline{\mathrm{H}}), 4.59\left(1 \mathrm{H}, \mathrm{dd}, J=10.8,1.7 \mathrm{~Hz}, \underline{\mathrm{H}}_{1}\right), 4.48\left(2 \mathrm{H}, \mathrm{s}, \mathrm{OC} \underline{\mathrm{H}}_{2} \mathrm{Ar}\right), 4.43(1 \mathrm{H}, \mathrm{dd}, J=$ $\left.14.0,3.4 \mathrm{~Hz}, \underline{\mathrm{H}}_{1 \mathrm{a}}\right), 4.19\left(1 \mathrm{H}, \mathrm{dd}, J=14.0,8.0 \mathrm{~Hz}, \underline{\mathrm{H}}_{\mathrm{bb}}\right), 3.66-3.61\left(1 \mathrm{H}, \mathrm{m}, \underline{\mathrm{H}}_{2}\right), 3.50-3.44\left(1 \mathrm{H}, \mathrm{m}, \underline{\mathrm{H}}_{5}\right)$, $3.46\left(2 \mathrm{H}, \mathrm{t}, J=6.6 \mathrm{~Hz}, \underline{\mathrm{H}}_{9}\right), 3.40-3.34\left(6 \mathrm{H}, \mathrm{m}, \underline{\mathrm{H}}_{10}+\underline{\mathrm{H}}_{11}+\underline{\mathrm{H}}_{16}\right), 3.24-3.18\left(1 \mathrm{H}, \mathrm{m}, \underline{\mathrm{H}}_{6}\right), 2.23\left(3 \mathrm{H}, \mathrm{s}, \underline{\mathrm{H}}_{23}\right)$, 2.04-1.83 (3H, m, $\left.\underline{\mathrm{H}}_{3 \mathrm{a}^{\mathrm{a}}}+\underline{\mathrm{H}}_{4}\right), 1.95\left(3 \mathrm{H}, \mathrm{s}, \underline{\mathrm{H}}_{21}\right), 1.65-1.14\left(29 \mathrm{H}, \mathrm{m}, \underline{\mathrm{H}}_{2^{\prime}-4},+\underline{\mathrm{H}}_{3 \mathrm{~b}}+\underline{\mathrm{H}}_{5}+\underline{\mathrm{H}}_{6^{\prime}-8^{\prime}}+\underline{\mathrm{H}}_{7-9}+\underline{\mathrm{H}}_{12-}\right.$ $\left.{ }_{15}\right) ;{ }^{13} \mathrm{C}$ NMR $\left(100 \mathrm{MHz}, \mathrm{CDCl}_{3}\right) \delta 158.8,150.0,149.9,145.3,138.8,128.5,127.8,127.6,122.4,117.4$, 117.1, 78.4, 77.9, 76.2, 73.3, 73.0, 71.0, 70.9, 70.5, 55.1, 39.1, 36.4, 36.2, 31.9, 31.4, 31.3, 29.9 (2C), 29.8 (2C), 28.8, 26.9, 26.1, 23.8, 23.1, 22.3, 22.2, 11.8, 9.9; HRMS (ESI ${ }^{+}$) Calc. for $\mathrm{C}_{41} \mathrm{H}_{62} \mathrm{O}_{6} \mathrm{~N}_{4} \mathrm{Na}$ $[\mathrm{M}+\mathrm{Na}]^{+} 729.4562$, found 729.4560 .

\subsubsection{N-(6-(4-((2S,6S)-6-((4-((2S,6S)-6-(4-(benzyloxy)butyl)tetrahydro-2H-pyran-2-yl)-1H-1,2,3-} triazol-1-yl)methyl)tetrahydro-2H-pyran-2-yl)butoxy)hexyl)-5-chlorofuran-2-carboxamide 31

The general procedure was followed using 5-chlorofuran-2-carboxylic acid (5.00 mg, $34.2 \mu \mathrm{mol}$ ). Purification by flash column chromatography (45\% EtOAc/Hexane) provided amide 31 (6.8 mg, 56\%), as a colourless oil.

$\mathbf{R}_{\mathbf{f}} 0.34\left(60 \%\right.$ EtOAc/Petrol); $[\alpha]_{\mathrm{D}}^{20}-16\left(c\right.$ 0.65, $\left.\mathrm{CHCl}_{3}\right)$; IR (ATR) 3300, 2934, 2857, 1717, 1647, 1599, $1533 \mathrm{~cm}^{-1} ;{ }^{1} \mathbf{H}$ NMR $\left(400 \mathrm{MHz}, \mathrm{CDCl}_{3}\right) \delta 7.60\left(1 \mathrm{H}, \mathrm{s}, \underline{\mathrm{H}}_{\mathrm{Ar}}\right), 7.33-7.24(5 \mathrm{H}, \mathrm{m}, \mathrm{ArH}), 7.07(1 \mathrm{H}, \mathrm{d}, J=$ $\left.3.5 \mathrm{~Hz}, \underline{\mathrm{H}}_{19}\right), 6.28\left(1 \mathrm{H}, \mathrm{d}, J=3.5 \mathrm{~Hz}, \underline{\mathrm{H}}_{20}\right), 6.27(1 \mathrm{H}$, br s, $\mathrm{N} \underline{\mathrm{H}}), 4.59\left(1 \mathrm{H}, \mathrm{dd}, J=10.9,1.9 \mathrm{~Hz}, \underline{\mathrm{H}}_{1}\right)$ ), $4.49\left(2 \mathrm{H}, \mathrm{s}, \mathrm{OCH}_{2} \mathrm{Ar}\right), 4.43\left(1 \mathrm{H}, \mathrm{dd}, J=14.0,3.4 \mathrm{~Hz}, \underline{\mathrm{H}}_{1 \mathrm{a}}\right), 4.19\left(1 \mathrm{H}, \mathrm{dd}, J=14.0,8.0 \mathrm{~Hz}, \underline{\mathrm{H}}_{1 \mathrm{~b}}\right), 3.66-$ 
$3.62\left(1 \mathrm{H}, \mathrm{m}, \underline{\mathrm{H}}_{2}\right), 3.50-3.44\left(1 \mathrm{H}, \mathrm{m}, \underline{\mathrm{H}}_{5}\right), 3.46\left(2 \mathrm{H}, \mathrm{t}, J=6.6 \mathrm{~Hz}, \underline{\mathrm{H}}_{9}\right), 3.41-3.34\left(6 \mathrm{H}, \mathrm{m}, \underline{\mathrm{H}}_{10}+\underline{\mathrm{H}}_{11}+\right.$ $\left.\underline{\mathrm{H}}_{16}\right)$, 3.24-3.19 (1H, m, $\left.\underline{\mathrm{H}}_{6}\right), 2.03-1.80\left(3 \mathrm{H}, \mathrm{m}, \underline{\mathrm{H}}_{3 \mathrm{a}^{\prime}}+\underline{\mathrm{H}}_{4}\right), 1.66-1.14\left(29 \mathrm{H}, \mathrm{m}, \underline{\mathrm{H}}_{2^{\prime}-4^{\prime}}+\underline{\mathrm{H}}_{3 \mathrm{~b}}+\underline{\mathrm{H}}_{5}+\underline{\mathrm{H}}_{6^{\prime}-8^{\prime}}+\right.$ $\left.\underline{\mathrm{H}}_{7-9}+\underline{\mathrm{H}}_{12-15}\right) ;{ }^{13} \mathbf{C} \mathbf{N M R}\left(100 \mathrm{MHz}, \mathrm{CDCl}_{3}\right) \delta 157.4,150.0,147.4,138.8,138.2,128.5,127.8,127.6$, 122.4, 116.2, 109.2, 78.4, 77.9, 76.3, 73.4, 73.0, 70.9 (2C), 70.5, 55.1, 39.3, 36.4, 36.2, 31.9, 31.4, 31.3, 30.0, 29.9, 29.8, 29.7, 28.8, 26.9, 26.1, 23.8, 23.1, 22.4, 22.3; HRMS (ESI ${ }^{+}$) Calc. for $\mathrm{C}_{39} \mathrm{H}_{57} \mathrm{O}_{6} \mathrm{~N}_{4} \mathrm{ClNa}$ $[\mathrm{M}+\mathrm{Na}]^{+}$735.3859, found 735.3843 .

\subsubsection{N-(6-(4-((2S,6S)-6-((4-((2S,6S)-6-(4-(benzyloxy)butyl)tetrahydro-2H-pyran-2-yl)-1H-1,2,3-} triazol-1-yl)methyl)tetrahydro-2H-pyran-2-yl)butoxy)hexyl)-5-nitrofuran-2-carboxamide 32

The general procedure was followed using 5-nitrofuran-2-carboxylic acid (5.40 mg, $34.2 \mu \mathrm{mol}$ ). Purification by flash column chromatography (20\% Acetone/Hexane) provided amide 32 (3.5 mg, 28\%), as a colourless oil.

$\mathbf{R}_{\mathbf{f}} 0.35$ (60\% EtOAc/Hexane); $[\alpha]_{\mathrm{D}}^{20}-15$ (c 0.55, $\left.\mathrm{CHCl}_{3}\right)$; IR (ATR) 3296, 2932, 2855, 1717, 1668, $1553 \mathrm{~cm}^{-1} ;{ }^{1} \mathbf{H}$ NMR $\left(500 \mathrm{MHz}, \mathrm{CDCl}_{3}\right) \delta 7.60\left(1 \mathrm{H}, \mathrm{s}, \underline{\mathrm{H}}_{\mathrm{Ar}}\right), 7.35\left(1 \mathrm{H}, \mathrm{d}, J=3.8 \mathrm{~Hz}, \underline{\mathrm{H}}_{19}\right), 7.33-7.27$ $(5 \mathrm{H}, \mathrm{m}, \mathrm{Ar} \underline{\mathrm{H}}), 7.24\left(1 \mathrm{H}, \mathrm{d}, J=3.8 \mathrm{~Hz}, \underline{\mathrm{H}}_{20}\right), 6.69(1 \mathrm{H}$, br s, $\underline{\mathrm{H}}), 4.59\left(1 \mathrm{H}, \mathrm{dd}, J=11.0,1.9 \mathrm{~Hz}, \underline{\mathrm{H}}_{1}{ }^{\prime}\right)$, $4.49\left(2 \mathrm{H}, \mathrm{s}, \mathrm{OCH}_{2} \mathrm{Ar}\right), 4.43\left(1 \mathrm{H}, \mathrm{dd}, J=14.0,3.4 \mathrm{~Hz}, \underline{\mathrm{H}}_{1 \mathrm{a}}\right), 4.19\left(1 \mathrm{H}, \mathrm{dd}, J=14.0,8.1 \mathrm{~Hz}, \underline{\mathrm{H}}_{1 \mathrm{~b}}\right), 3.66-$ $3.63\left(1 \mathrm{H}, \mathrm{m}, \underline{\mathrm{H}}_{2}\right), 3.49-3.41\left(3 \mathrm{H}, \mathrm{m}, \underline{\mathrm{H}}_{5},+\underline{\mathrm{H}}_{16}\right), 3.46\left(2 \mathrm{H}, \mathrm{t}, J=6.6 \mathrm{~Hz}, \underline{\mathrm{H}}_{9}\right), 3.41-3.34\left(4 \mathrm{H}, \mathrm{m}, \underline{\mathrm{H}}_{10}+\right.$ $\left.\underline{\mathrm{H}}_{11}\right), 3.23-3.19\left(1 \mathrm{H}, \mathrm{m}, \underline{\mathrm{H}}_{6}\right), 2.04-1.80\left(3 \mathrm{H}, \mathrm{m}, \underline{\mathrm{H}}_{3 \mathrm{a}}{ }^{\prime}+\underline{\mathrm{H}}_{4}\right), 1.66-1.13\left(29 \mathrm{H}, \mathrm{m}, \underline{\mathrm{H}}_{2}{ }^{\prime}-4^{\prime}+\underline{\mathrm{H}}_{3 \mathrm{~b}}+\underline{\mathrm{H}}_{5}+\underline{\mathrm{H}}_{6^{\prime}-8^{\prime}}+\right.$ $\left.\underline{\mathrm{H}}_{7-9}+\underline{\mathrm{H}}_{12-15}\right) ;{ }^{13} \mathbf{C}$ NMR $\left(125 \mathrm{MHz}, \mathrm{CDCl}_{3}\right) \delta 156.4,151.5,150.0,148.4,138.8,128.5,127.8,127.6$, 122.4, 115.9, 112.7, 78.4, 77.9, 76.2, 73.3, 73.0, 70.9, 70.8, 70.5, 55.1, 39.7, 36.4, 36.2, 31.9, 31.3, 29.9, 29.8, 29.7, 29.6, 28.8, 26.9, 26.0, 23.8, 23.1, 22.3, 22.2; HRMS (ESI ${ }^{+}$) Calc. for $\mathrm{C}_{39} \mathrm{H}_{57} \mathrm{O}_{8} \mathrm{~N}_{5} \mathrm{Na}$ $[\mathrm{M}+\mathrm{Na}]^{+} 746.4099$, found 746.4085 .

\subsubsection{1 $N$-(6-methoxyhexyl)furan-2-carboxamide 33}

To a solution of $N$-(6-hydroxyhexyl)-1-methyl-1H-pyrazole-5-carboxamide S9 (10.0 mg, $4.44 \mu \mathrm{mol})$ and 1,8-bis(dimethylamino)naphthalene $(32.9 \mathrm{mg}, 221 \mu \mathrm{mol})$ in dry $\mathrm{CH}_{2} \mathrm{Cl}_{2}(2 \mathrm{~mL})$ at $0{ }^{\circ} \mathrm{C}$ was added trimethyloxonium tetrafluoroborate $(47.4 \mathrm{mg}, 221 \mu \mathrm{mol})$ and the mixture stirred at RT for $72 \mathrm{~h}$. The mixture was cooled to $0{ }^{\circ} \mathrm{C}$ and reaction quenched with saturated $\mathrm{NH}_{4} \mathrm{OH}$ solution $(0.5 \mathrm{~mL})$. Saturated $\mathrm{NaHCO}_{3}$ solution $(5 \mathrm{~mL})$ was added and the organics extracted with $\mathrm{CH}_{2} \mathrm{Cl}_{2}(3 \times 5 \mathrm{~mL})$. The combined organic extracts were washed with $0.3 \mathrm{~N} \mathrm{HCl}$ solution, dried $\left(\mathrm{MgSO}_{4}\right)$, filtered and concentrated in 
vacuo Purification by flash column chromatography (65\% EtOAc/Hexane) provided ether 33 (5.5 mg, $52 \%$ ), as a colourless oil.

$\mathbf{R}_{\mathbf{f}} 0.34$ (75\% EtOAc/Hexane); IR (ATR) 3310, 2930, 2858, 1645, $1543 \mathrm{~cm}^{-1} ;{ }^{1} \mathbf{H}$ NMR (500 MHz, $\left.\mathrm{CDCl}_{3}\right) \delta 7.43\left(1 \mathrm{H}, \mathrm{d}, J=1.8 \mathrm{~Hz}, \underline{\mathrm{H}}_{10}\right), 6.46\left(1 \mathrm{H}, \mathrm{d}, J=1.8 \mathrm{~Hz}, \underline{\mathrm{H}}_{11}\right), 6.01(1 \mathrm{H}, \mathrm{br} \mathrm{s}, \mathrm{NH}), 4.17(3 \mathrm{H}, \mathrm{s}$, $\left.\underline{\mathrm{H}}_{12}\right), 3.41-3.36\left(4 \mathrm{H}, \mathrm{m}, \underline{\mathrm{H}}_{2}+\underline{\mathrm{H}}_{7}\right), 3.32\left(3 \mathrm{H}, \mathrm{s}, \underline{\mathrm{H}}_{1}\right), 1.63-1.57\left(4 \mathrm{H}, \mathrm{m}, \underline{\mathrm{H}}_{3}+\underline{\mathrm{H}}_{6}\right), 1.41-1.38\left(4 \mathrm{H}, \mathrm{m}, \underline{\mathrm{H}}_{4}+\right.$ $\left.\underline{\mathrm{H}}_{5}\right) ;{ }^{13} \mathrm{C}$ NMR $\left(125 \mathrm{MHz}, \mathrm{CDCl}_{3}\right) \delta 160.1,137.7,135.5,106.0,72.8,58.7,39.6,39.4,29.7,29.6,26.9$, 26.0; HRMS $\left(\right.$ ESI $\left.^{+}\right)$Calc. for $\mathrm{C}_{12} \mathrm{H}_{21} \mathrm{O}_{3} \mathrm{~N}_{2} \mathrm{Na}[\mathrm{M}+\mathrm{Na}]^{+}$262.1526, found 262.1526.

\subsubsection{N-(6-methoxyhexyl)furan-2-carboxamide 34}

To a solution of $N$-(6-hydroxyhexyl)furan-2-carboxamide $\mathbf{S 1 0}(8.00 \mathrm{mg}, 37.9 \mu \mathrm{mol})$ and 1,8bis(dimethylamino)naphthalene $(81.0 \mathrm{mg}, 379 \mu \mathrm{mol})$ in dry $\mathrm{CH}_{2} \mathrm{Cl}_{2}(2 \mathrm{~mL})$ at $0{ }^{\circ} \mathrm{C}$ was added trimethyloxonium tetrafluoroborate $(56.0 \mathrm{mg}, 379 \mu \mathrm{mol})$ and the mixture stirred at RT for $72 \mathrm{~h}$. The mixture was cooled to $0{ }^{\circ} \mathrm{C}$ and reaction quenched with saturated $\mathrm{NH}_{4} \mathrm{OH}$ solution $(0.5 \mathrm{~mL})$. Saturated $\mathrm{NaHCO}_{3}$ solution $(5 \mathrm{~mL})$ was added and the organics extracted with $\mathrm{Et}_{2} \mathrm{O}(3 \mathrm{x} 5 \mathrm{~mL})$. The combined organic extracts were washed with $1 \mathrm{~N} \mathrm{HCl}$ solution, dried $\left(\mathrm{MgSO}_{4}\right)$, filtered and concentrated in vacuo Purification by flash column chromatography (40\% EtOAc/Petrol) provided ether 34 (7.6 mg, 89\%), as a colourless oil.

$\mathbf{R}_{\mathbf{f}} 0.36$ (50\% EtOAc/Petrol); IR (ATR) 3302, 2930, 2859, 1643, 1593, 1572, $1530 \mathrm{~cm}^{-1}$; ${ }^{1} \mathbf{H}$ NMR (400 $\left.\mathrm{MHz} \mathrm{CDCl}_{3}\right) \delta 7.42\left(1 \mathrm{H}, \mathrm{dd}, J=1.8,0.8 \mathrm{~Hz}, \underline{\mathrm{H}}_{12}\right), 7.09\left(1 \mathrm{H}, \mathrm{dd}, J=3.5,0.8 \mathrm{~Hz}, \underline{\mathrm{H}}_{10}\right), 6.48(1 \mathrm{H}, \mathrm{dd}, J=$ $\left.3.5,1.8 \mathrm{~Hz}, \underline{\mathrm{H}}_{11}\right), 6.35(1 \mathrm{H}$, br s, $\underline{\mathrm{H}}), 3.41\left(2 \mathrm{H}\right.$, app q, $\left.J=6.9 \mathrm{~Hz}, \underline{\mathrm{H}}_{7}\right), 3.35\left(2 \mathrm{H}, \mathrm{t}, J=6.5 \mathrm{~Hz}, \underline{\mathrm{H}}_{2}\right), 3.32$ $\left(3 \mathrm{H}, \mathrm{s}, \underline{\mathrm{H}}_{1}\right), 1.62-1.54\left(4 \mathrm{H}, \mathrm{m}, \underline{\mathrm{H}}_{3}+\underline{\mathrm{H}}_{6}\right), 1.41-1.37\left(4 \mathrm{H}, \mathrm{m}, \underline{\mathrm{H}}_{4}+\underline{\mathrm{H}}_{5}\right) ;{ }^{13} \mathbf{C} \mathbf{N M R}\left(100 \mathrm{MHz}, \mathrm{CDCl}_{3}\right) \delta$ 158.5, 148.3, 143.8, 114.1, 112.2, 72.9, 58.7, 39.2, 29.8, 29.7, 26.9, 26.0; HRMS (ESI ${ }^{+}$) Calc. for $\mathrm{C}_{12} \mathrm{H}_{19} \mathrm{O}_{3} \mathrm{NNa}[\mathrm{M}+\mathrm{Na}]^{+} 248.1257$, found 248.1254.

\subsubsection{N-(6-methoxyhexyl)-5-nitrofuran-2-carboxamide 35}

To a solution of $\mathrm{N}$-(6-hydroxyhexyl)-5-nitrofuran-2-carboxamide $\mathbf{S 1 1}$ (9.70 $\mathrm{mg}, 37.9 \mu \mathrm{mol})$ and 1,8bis(dimethylamino)naphthalene $(81.0 \mathrm{mg}, 379 \mu \mathrm{mol})$ in dry $\mathrm{CH}_{2} \mathrm{Cl}_{2}(2 \mathrm{~mL})$ at $0{ }^{\circ} \mathrm{C}$ was added trimethyloxonium tetrafluoroborate $(56.0 \mathrm{mg}, 379 \mu \mathrm{mol})$ and the mixture stirred at RT for $72 \mathrm{~h}$. The mixture was cooled to $0{ }^{\circ} \mathrm{C}$ and reaction quenched with saturated $\mathrm{NH}_{4} \mathrm{OH}$ solution $(0.5 \mathrm{~mL})$. Saturated $\mathrm{NaHCO}_{3}$ solution $(5 \mathrm{~mL})$ was added and the organics extracted with $\mathrm{Et}_{2} \mathrm{O}(3 \times 5 \mathrm{~mL})$. The combined 
organic extracts were washed with $1 \mathrm{~N} \mathrm{HCl}$ solution, dried $\left(\mathrm{MgSO}_{4}\right)$, filtered and concentrated in vacuo Purification by flash column chromatography (30\% EtOAc/Petrol) provided ether 35 (3.3 mg, 32\%), as a colourless oil.

$\mathbf{R}_{\mathbf{f}} 0.50$ (50\% EtOAc/Petrol); IR (ATR) 3300, 2932, 2859, 1653, 1584, 1553, $1528 \mathrm{~cm}^{-1} ;{ }^{1} \mathbf{H}$ NMR (400 $\left.\mathrm{MHz}, \mathrm{CDCl}_{3}\right) \delta 7.36\left(1 \mathrm{H}, \mathrm{d}, J=3.8 \mathrm{~Hz}, \underline{\mathrm{H}}_{10}\right), 7.25\left(1 \mathrm{H}, \mathrm{d}, J=3.8 \mathrm{~Hz}, \underline{\mathrm{H}}_{11}\right), 6.61(1 \mathrm{H}, \mathrm{br} \mathrm{s}, \mathrm{NH}), 3.45$ $\left(2 \mathrm{H}\right.$, app q, $\left.J=7.0 \mathrm{~Hz}, \underline{\mathrm{H}}_{7}\right), 3.37\left(2 \mathrm{H}, \mathrm{t}, J=6.5 \mathrm{~Hz}, \underline{\mathrm{H}}_{2}\right), 3.33\left(3 \mathrm{H}, \mathrm{s}, \underline{\mathrm{H}}_{1}\right), 1.66-1.57\left(4 \mathrm{H}, \mathrm{m}, \underline{\mathrm{H}}_{3}+\underline{\mathrm{H}}_{6}\right)$, 1.42-1.39 (4H, m, $\left.\underline{\mathrm{H}}_{4}+\underline{\mathrm{H}}_{5}\right) ;{ }^{13} \mathbf{C}$ NMR (100 MHz, $\left.\mathrm{CDCl}_{3}\right) \delta 156.3,148.4,115.9,112.6,72.8,58.7,39.7$, 29.6, 29.6, 26.9, 26.0; HRMS (ESI ${ }^{+}$) Calc. for $\mathrm{C}_{12} \mathrm{H}_{18} \mathrm{O}_{5} \mathrm{~N}_{2} \mathrm{Na}[\mathrm{M}+\mathrm{Na}]^{+}$293.1108, found 293.1104 .

\subsection{Biological Testing}

\subsubsection{Cell culture}

Bloodstream form T. brucei brucei strain 427 were grown in HMI-9 media supplemented with 10\% foetal bovine serum (Gibco) and $2.5 \mu \mathrm{g} / \mathrm{mL}$ G418 (Calbiochem) at $37^{\circ} \mathrm{C}$ with $5 \% \mathrm{v} / \mathrm{v} \mathrm{CO}_{2}$ with $10 \%$ bovine serum and G418 $(2.5 \mu \mathrm{g} / \mathrm{mL})$ at $37^{\circ} \mathrm{C}$ with $5 \% \mathrm{v} / \mathrm{v} \mathrm{CO}_{2}$, as described elsewhere. ${ }^{8}$ Procyclic form T. brucei brucei strain 29-13 were grown in SDM-79 media (Gibco) supplemented with 2g/L sodium bicarbonate (Fisher Scientific), $7.5 \mu \mathrm{g} / \mathrm{mL}$ haemin (Sigma) 10\% foetal bovine serum, $12.5 \mu \mathrm{g} / \mathrm{mL}$ G418 and $25 \mu \mathrm{g} / \mathrm{mL}$ hygromycin (Formedium) at $27.5^{\circ} \mathrm{C}$ with $5 \% \mathrm{v} / \mathrm{v} \mathrm{CO}_{2}$.

HeLa cells (ATCC® CCL-2) and African Green monkey kidney Vero cells (ECACC 84113001) were cultured in Dulbecco's Modified Eagle Medium (DMEM, Sigma) supplemented with 10\% foetal bovine serum and grown at $37^{\circ} \mathrm{C}$ in $5 \% \mathrm{CO}_{2}$ atmosphere.

Epimastigote Trypanosoma cruzi CL Brener strain were grown at $28{ }^{\circ} \mathrm{C}$ in RPMI 1640 medium (Sigma) supplemented with $20 \mathrm{mM}$ HEPES pH 7.2 (Sigma), $4.9 \mathrm{mg} / \mathrm{mL}$ tryptone (Sigma), PGAB (2 mM sodium glutamate, $2 \mathrm{mM}$ sodium pyruvate, $100 \mu \mathrm{g} / \mathrm{mL}$ streptomycin and $100 \mathrm{U} / \mathrm{mL}$ penicillin, all Sigma), 20 $\mu \mathrm{g} / \mathrm{mL}$ haemin and $10 \%$ heat-inactivated foetal bovine serum.

Promastigote L. major MHOM/IL/80/Friedlin were grown at $28{ }^{\circ} \mathrm{C}$ in M199 media (Sigma) pH 7.4, supplemented with $40 \mathrm{mM}$ HEPES $\mathrm{pH}$ 7.4, $100 \mu \mathrm{M}$ adenosine, $5 \mu \mathrm{g} / \mathrm{mL}$ haemin and 10\% heatinactivated foetal bovine serum.

\subsubsection{Cytotoxicity assays}


The determination of the $\mathrm{EC}_{50}$ of the compounds using Alamar Blue was completed as previously described. ${ }^{29}$ Briefly, compounds were made up in DMSO and two-fold serial dilutions of compound in media were carried out in a 96-well plate in quadruplicate. Cells were counted using CASY Cell Counter and seeded as specified below.

Bloodstream form parasites, procyclic form parasites and HeLa cells were plated out at $1 \times 10^{3}$ cells/well, $1 \times 10^{4}$ cells/well and $1 \times 10^{3}$ cells/well, respectively. After 64 hours (3 days) Alamar Blue was added to each well and left for 6-8 hours to develop.

Mid-log L. major were diluted in media and seeded at $2 \times 10^{5}$ per well in $100 \mu \mathrm{L}$ media. Negative controls of DMSO only were included. Plates were incubated at $28{ }^{\circ} \mathrm{C}$ for 72 hours, after which $20 \mu \mathrm{L}$ Alamar Blue (12.5 mg resazurin salt in $100 \mathrm{~mL}$ PBS) was added to all wells and incubated for a further 6 hours.

Mid-log T. cruzi were diluted in media and seeded at $5 \times 10^{5}$ per well in $100 \mu \mathrm{L}$ media. Negative controls of DMSO only and positive control of nifurtimox were included. Plates were incubated at $28^{\circ} \mathrm{C}$ for 72 hours, after which $10 \mu \mathrm{L}$ Alamar Blue was added to all wells and incubated for a further 6 hours.

For Vero cell assays, the monolayer was trypsinized, diluted in media and cells were seeded at $4 \times 10^{3}$ cells per well. Cells were incubated at $37^{\circ} \mathrm{C}$ with $5 \% \mathrm{CO}_{2}$ for 24 hours to allow attachment, after which media was removed and replaced with fresh media containing serial dilutions of compound. Drug diluted in media was added and plates were incubated for 72 hours, after which $10 \mu \mathrm{L}$ Alamar Blue was added to all wells and incubated for a further 2 hours.

Cell viability was quantified using an FLx 800 plate reader (BioTek) with excitation wavelength 540/35 $\mathrm{nm}$ and emission wavelength at 590/10 nm using Gen5 Reader Control 2.0 Software (BioTek). EC 50 values were determined using a 4-parameter logistic regression equation using GraFit 5.0 (Erithacus Software).

\section{Acknowledgements}

This work was funded by the Leverhulme Trust. We thank the EPSRC National Mass Spectrometry Service Centre, Swansea, UK for mass spectrometry services.

The research data supporting this publication can be accessed at http://dx.doi.org/10.17630/1dd8b88117c2-48e4-a72f-53af938f4537 


\section{Supplementary Information}

Supplementary Information (synthesis and characterisation of intermediates, screening against procyclic T. brucei) associated with this article can be found in the online version.

\section{References and notes}

${ }^{1}$ Lozano, R.; Naghavi, M.; Foreman, K.; Lim, S.; Shibuya, K.; Aboyans, V. and others Lancet 2012, $380,2095-2128$.

${ }^{2}$ World Health Organisation: Geneva, 2016: Neglected tropical diseases.

www.who.int/neglected_diseases/en/ (Accessed 24 October, 2016).

${ }^{3}$ Zhou, L.; Stewart, G.; Rideau, E.; Westwood, N. J.; Smith, T. K. J. Med. Chem. 2013, 56, 796 - 806.

${ }^{4}$ Matthews, K. R. Mol. Biochem. Parasitol. 2015, 200, 30 - 40.

${ }^{5}$ Gaspar, L.; Moraes, C. B.; Freitas-Junior, L. H.; Ferrari, S.; Costantino, L.; Costi, M. P.; Coron, R. P.; Smith, T. K.; Siqueira-Neto, J. L.; McKerrow, J. H.; Cordeiro-da-Silva, A. Curr. Med. Chem. 2015, 22, 4293-4312.

${ }^{6}$ Nagle, A. S.; Khare, S.; Kumar, A. B.; Supek, F.; Buchynskyy, A.; Mathison, C. J. N.; Chennamaneni, N. K.; Pendem, N.; Buckner, F. S.; Gelb, M. H.; Molteni, V. Chem. Rev. 2014, 114, 11305 - 11347.

${ }^{7}$ Hotez, P. J.; Dumonteil, E.; Cravioto, M. B.; Bottazzi, M. E.; Tapia-Conyer, R.; Meymandi, S.; Karunakara, U.; Ribeiro, I.; Cohen, R. M.; Pecoul, B. PLOS Negl Trop Dis 2013, 7, e2300.

${ }^{8}$ World Health Organization, Switzerland, 2010: First WHO report on neglected tropical diseases: working to overcome the global impact of neglected tropical diseases.

${ }^{9}$ a) Steverding, D. Parasit. Vectors 2010, 3, 15; b) Delespaux, V.; de Koning, H. P. Drug Resistance Updates 2007, 10, 30 - 50.

${ }^{10}$ For other examples of potential broad-spectrum kinetoplastid inhibitors see: Di Pietro, O.; VicenteGarcía, E.; Taylor, M. C.; Berenguer, D.; Viayna, E.; Lanzoni, A.; Sola, I.; Sayago, H.; Riera, C.; Fisa, R.; Clos, M. V.; Pérez, B.; Kelly, J. M.; Lavilla, R.; Muñoz-Torrero, D. Eur. J. Med. Chem. 2015, 105, 120 - 137; Annang, F.; Pérez-Moreno, G.; García-Hernández, R.; Cordon-Obras, C.; Martín, J.; Tormo, J. R.; Rodríguez, L.; de Pedro, N.; Gómez-Pérez, V.; Valente, M.; Reyes, F.; Genilloud, O.; Vicente, F.; Castanys, S.; Ruiz-Pérez, L. M.; Navarro, M.; Gamarro, F.; González-Pacanowska, D. J. Biomol. Screen. 2015, 20, 82 - 91; Manda, S.; Khan, S. I.; Jain, S. K.; Mohammed, S.; Tekwani, B. L.; Khan, I. A.; Vishwakarma, R. A.; Bharate, S. B. Bioorg. Med. Chem. Lett. 2014, 24, 3247 - 3250.

11 a) Mbaya, A. W.; Ibrahim, U. I. Int. J. Pharmacol 2011, 7, 1 - 11; b) Assi, L. A.; Guinko, S. Plants used in Traditional Medicine in West Africa; 1991; Friedrich Reinhardt AG.

12 a) Bermejo, A.; Figadère, B.; Zafra-Polo, M.-C.; Barrachina, I.; Estornell E.; Cortes, D. Nat. Prod. Rep. 2005, 22, 269 - 303; b) Spurr, I. B.; Brown, R .C. D. Molecules 2010, 15, 460 - 501; c) Alali, F. Q.; Liu, X.-X.; McLaughlin, J. L. J. Nat. Prod. 1999, 62, $504-540$.

${ }^{13}$ Liaw, C.- C.; Liou, J.-R.; Wu, T. -Y.; Chang, F. -R.; Wu, Y. -C. Acetogenins from Annonaceae, in: Kinghorn, A. D; Falk, H.; Gibbons, S.; Kobayashi, J (Eds.) Progress in the Chemistry of Organic Natural Products 101, Springer International Publishing AG, Switzerland, 2016, pp. 113 - 230.

${ }^{14}$ Kojima, N.; Tanaka, T. Molecules 2009, 14, 3621 - 3661 and references cited therein.

15 a) Ogbadoyi, E. O.; Abdulganiy, A. O.; Adama, T. Z.; Okogun, J. I. J. Ethnopharmacol. 2007, 112, 85 - 89; b) Freiburghaus, F.; Jonker, S. A.; Nkunya, M. H. H.; Mwasumbi, L. B.; Brun, R. Acta Tropica 
1997, 67, 181 - 185; c) F. Freiburghaus, Kaminsky, R.; Nkunya, M.H.H.; Brun, R. J. Ethnopharmacol. 1996, 55, 1-11; d) Igweh, A. C.; Onabanjo, A. O. Ann. Trop. Med. Parasit. 1989, 83, $527-534$.

${ }^{16}$ Hoet, S.; Opperdoes, F.; Brun, R.; Quetin-Leclercq, J. Nat. Prod. Rep. 2004, 21, 353 - 364.; Sahpaz, S.; Bories, C.; Loiseau, P. M.; Cortès, D.; Hocquemiller, R.; Laurens, A.; Cavé, A. Planta. Med. 1994, $60,538-540$.

${ }^{17}$ a) Lima, L. A. R. S.; Alves, T. M. A.; Zani, C. L.; Sales Júnior, P. A.; Romanha, A. J.; Johann, S.; Cisalpino, P. S.; Pimenta, L. P. S.; Boaventura, M. A. D. An Acad Bras Cienc 2014, 86, 829 - 839; b)

Février, A.; Ferreira, M. E.; Fournet, A.; Yaluff, G.; Inchausti, A.; de Arias, A. R.; Hocquemiller, R.; Waechter, A. -I. Planta Medica 1999, 65, 47 - 49; c) Waechter, A. -I.; Yaluff, G.; Inchausti, A.; de Arias, A. R.; Hocquemiller, R.; Cavé, A.; Fournet, A. Phytother. Res. 1998, 12, 541 - 544.

${ }^{18}$ Fall, D.; Duval, R. A.; Gleye, C.; Laurens, A.; Hocquemiller, R. J. Nat. Prod. 2004, 67, 1041 - 1043.

19 a) Florence, G. J.; Morris, J. C.; Murray, R. G.; Vanga, R. R.; Osler, J. D.; Smith, T. K. Chem. Eur. J. 2013, 19, 8309 - 8320; b) Florence, G. J.; Morris, J. C.; Murray, R. G.; Osler, J. D.; Vanga, R. R.; Smith, T. K. Org. Lett. 2011, 13, $514-517$.

${ }^{20}$ a) Florence, G. J.; Fraser, A. L.; Gould, E. R.; King, E. F.; Menzies, S. K.; Morris, J. C.; Tulloch, L. B.; Smith, T. K. ChemMedChem 2016, 11, 1503 - 1506; b) Florence, G. J.; Fraser, A. L.; Gould, E. R.; King, E. F.; Menzies, S. K.; Morris, J. C.; Tulloch, L. B.; Smith, T. K. ChemMedChem 2014, 9,2548 2556.

${ }^{21}$ a) Kojima, N.; Fushimi, T.; Tatsukawa, T.; Tanaka, T.; Okamura, M.; Akatsuka, A.; Yamori, T.; Dan, S.; Iwasaki, H.; Yamashita, M. Eur. J. Med. Chem. 2014, 86, 684 - 689; b) Kojima, N.; Fushimi, T.;

Tatsukawa, T.; Yoshimitsu, T.; Tanaka, T.; Yamori, T.; Dan, S.; Iwasaki, H.; Yamashita, M. Eur. J. Med. Chem. 2013, 63, $833-839$.

${ }^{22}$ Gilbert, I. H. J. Med. Chem. 2013, 56, $7719-7726$.

${ }^{23}$ See Supporting Information for detailed synthetic procedures.

${ }^{24}$ Schaus, S. E.; Brandes, B. D.; Larrow, J. F.; Tokunaga, M.; Hansen, K. B.; Gould, A. E.; Furrow, M. E.; Jacobsen, E. N. J. Am. Chem. Soc 2002, 124, 1307 - 1315.

${ }^{25}$ New compounds have additionally been screened against the procyclic form of T. brucei brucei, see Supporting Information for details.

${ }^{26}$ The poor activity of diol 16 is consistent with data in our previous series, see ref $20 \mathrm{~b}$ for details

${ }^{27}$ Khare, S.; Nagle, A. S.; Biggart, A.; Lai, Y. H.; Liang, F.; Davis, L. C.; Barnes, S. W.; Mathison, C. J. N.; Myburgh, E.; Gao, M.- Y.; Gillespie, J. R.; Liu, X.; Tan, J. L.; Stinson, M.; Rivera, I. C.; Ballard, J.; Yeh, V.; Groessl, T.; Federe, G.; Koh, H. X. Y.; Venable, J. D.; Bursulaya, B.; Shapiro, M.; Mishra, P. K.; Spraggon, G.; Brock, A.; Mottram, J. C.; Buckner, F. S.; Rao, S. P. S.; Wen, B. G.; Walker, J. R.; Tuntland, T.; Molteni, V.; Glynne, R. J.; Supek, F. Nature 2016, 537, 229 - 233.

${ }^{28}$ a) Kaiser, M.; Bray, M. A.; Cal, M.; Trunz, B. B.; Torreele, E.; Brun, R. Antimicrob. Agents Chemother. 2011, 55, 5602 - 5608; b) Sokolova, A. Y.; Wyllie, S.; Patterson, S.; Oza, S. L.; Read, K. D.; Fairlamb, A. H. Antimicrob. Agents Chemother. 2010, 54, $2893-2900$.

${ }^{29}$ Hirumi, H.; Hirumi, K. J Parasitol 1989, 75, 985 - 989. 